\title{
The importance of the financial system for the real economy
}

\author{
Sebastian Ankargren ${ }^{1}$ - Mårten Bjellerup ${ }^{2}$. \\ Hovick Shahnazarian ${ }^{3}$
}

Received: 19 February 2015 / Accepted: 12 August 2016 / Published online: 27 September 2016 (C) The Author(s) 2016. This article is published with open access at Springerlink.com

\begin{abstract}
This paper first describes financial variables that have been constructed to correspond to various channels in the transmission mechanism. Next, a Bayesian VAR model for the macroeconomy, with priors on the steady states, is augmented with these financial variables and estimated using Swedish data for 1989-2015. The results support three conclusions. First, the financial system is important and the strength of the results is dependent on identification, with the financial variables accounting for $10-25 \%$ of the forecast error variance of Swedish GDP growth. Second, the suggested model produces an earlier signal regarding the probability of recession, compared to a model without financial variables. Third, the model's forecasts for the deep downturn in 2008 and 2009, conditional on the development of the financial variables, outperform a macro-model that lacks financial variables. Furthermore, this improvement in modelling Swedish GDP growth during the financial crisis does not come at the expense of unconditional predictive power. Taken together, the results suggest that the proposed model presents an accessible possibility to analyse the macro-financial linkages and the GDP developments, especially during a financial crisis.
\end{abstract}

Keywords Transmission channels $\cdot$ Financial indicators $\cdot$ Macroeconomy $\cdot$ Business cycle $\cdot$ Credit cycle $\cdot$ Bayesian VAR

JEL Classification E37 · E44

Sebastian Ankargren

Sebastian.Ankargren@statistics.uu.se

1 Department of Statistics, Uppsala University, Box 513, 75120 Uppsala, Sweden

2 Swedish National Debt Office, 10374 Stockholm, Sweden

3 Ministry of Finance, 10333 Stockholm, Sweden 


\section{Introduction}

In late 2008, during the peak of the financial crisis, several markets at the heart of the financial system more or less stopped functioning. Liquidity in the interbank market dried up as banks refrained from lending money, even at short maturities. The price of many assets fell quickly and deeply, central banks cut their policy rates drastically, and the situation was characterized by great uncertainty. The crisis deepened the incipient recession sharply, and most economists and policy makers were, at the time, surprised by the dramatic effects on the real economy. But the close link between the financial system and the real economy is not only there in times of crisis; it is also in place under more normal economic circumstances. The effects are just less drastic.

In the wake of the financial crisis, researchers and policy makers have directed much more attention to the linkage between the financial system and the real economy, known as the transmission mechanism. ${ }^{1}$ Great theoretical and empirical effort has been devoted to better understand the way financial shocks affect the real economy (see, for example, Bloom 2009; Bloom et al. 2012; Christiano et al. 2014). An important part of the increased attention is that several governments are now considering more far-reaching changes in supervisory and regulatory structures in order to protect the real economy from the recurrent malfunctioning of the financial sector. ${ }^{2}$

However, if regulation is to be successful, at least two conditions have to be fulfilled. First, policy makers need to have a qualitative knowledge of how the financial markets affect the real economy through the transmission mechanism. Second, policy makers need to have quantitative knowledge of the transmission mechanism in order to make a balanced choice of the magnitude of a specific regulative measure.

Early efforts on modelling the transmission mechanism have largely focused on modelling individual channels within the transmission mechanism, while later efforts, not least within the dynamic stochastic general equilibrium (DSGE) literature, have a richer modelling of the transmission mechanism. ${ }^{3}$ It should be pointed out that there are many studies that examine what effect individual transmission channels have on the real economy. There are to our knowledge no empirical papers that estimate the impact of all transmission channels. ${ }^{4}$ The idea of this paper is to fill this gap by suggesting a description of the transmission mechanism that fits into a small-scale Bayesian VAR (BVAR) model. Despite being limited in terms of variables, the model offers a number of possibilities in analysing various developments in financial markets. The reason is that the financial variables used in the model are composites of several financial variables, which in turn stem from the detailed underlying description of the transmission mechanism. BVAR models resembling the one used in this paper have

\footnotetext{
1 See, for instance, Basel Committee (2011).

2 See, for instance, Basel Committee (2012a).

3 See the survey from Basel Committee (2012b) and Brunnermeier et al. (2012). Jermann and Quadrini (2012) and Christiano et al. (2014) are examples of two structural DSGE models that include financial frictions in their models.

4 However, there are general equilibrium models with a much more detailed modelling of the economy that take account of several transmission channels at the same time. See, for example, Brunnermeier et al. (2012)
} 
been successfully used in related applied work (see, for example, Österholm 2010; Jarocinski and Smets 2008 among others).

The model is essentially used to answer two questions: (i) Is the financial system important for the development in the real economy? (ii) If it is, what are the characteristics?

The paper has the following structure. In Sect. 2, we construct four composite financial variables that act as indicators for the transmissions channels using data from Sweden. In Sect. 3, the details of the statistical model of our choice, a BVAR model with a prior on the steady state, are given. In Sect. 4, the model is used to answer the two questions we have posed. Moreover, Sect. 4 investigates the robustness of the results by conducting a sensitivity analysis. Section 5 concludes.

\section{Choice and construction of the financial variables}

The financial system mainly affects the real economy through the following transmission channels: the balance sheet channel, the interest rate channel, the bank capital channel and the uncertainty channel. "Appendix" describes negative external effects that cause the accumulation and liquidation of financial imbalances and the way the identified negative externalities affect the real economy through the different transmission channels. The purpose of this section is to describe the variables that we use to quantify and isolate the impact of different transmissions channels on the real economy.

\subsection{Asset price gap and credit gap: the balance sheet channel}

The balance sheet channel describes how falling asset prices affect households and firms' balance sheet, solvency and creditworthiness, and the impact that this may have on consumption and investment. The prices of financial and real assets are important for the solvency of firms and households. In order to capture the variations in both financial and real asset prices, a summary index is therefore created based on how the share and property prices change in relation to their historical trends. A gap is generated for each of the stock and property markets as a first step towards creating a summary variable. The stock price gap and the house price gap are defined as the deviation of the stock market index and the property price index from their trend divided by the trend. ${ }^{5}$ In the second step, the share price gap $(20 \%)$ and the property price gap (80\%) are combined in an asset price gap that summarizes the development of house and stock prices. ${ }^{6}$

\footnotetext{
5 The trend is calculated through a one-sided HP filter using a value of the weighting parameter equal to 400000 (see, for example, Drehmann et al. 2010). The Basel Committee suggests using this method to calculate the credit gap which is the deviation of the credit-to-GDP ratio from its long-term trend. The study by Drehmann et al. (2010) indicates that the credit gap has been useful in signalling financial crises in the past.

6 Although the weighting is subjective, the aim has been to find weights that create a clear linkage between the wealth gap and the GDP growth. The size of the weights also corresponds to the relative size of the variance of the share price and property price gaps. We have also estimated the model with individual series
} 
Economic shocks lead to a fall in the value of borrowers' assets at the same time as the value of their loans is unchanged. In such cases, the borrowers' balance sheets look much worse than they had expected, with the result that they amortize part of their liabilities (consolidate their balance sheets). So, asset prices and credit can reinforce each other through the "financial accelerator effect". To be able to control for this mechanism, we include a credit gap to the set of variables. Technically, the credit gap is constructed in the same way as the share price gap. As a first step the credit ratio is generated (total lending in relation to GDP at current prices). The credit gap is defined as the deviation of the credit ratio from its trend, divided by the trend.

\subsection{The interest on three months treasury bills: the interest rate channel}

The interest rate channel describes how the real economy is affected when the central bank increases the repo rate. Monetary policy affects the interest on three months treasury bills by changing the repo rate which is equivalent to changing the so-called overnight rate. 7

Monetary policy also affects the value of the currency (exchange rate channel). Normally, an increase in the repo rate leads to a strengthening of the krona. A stronger exchange rate-an appreciation-makes foreign goods cheaper compared with domestically produced goods which lead to a rise in imports, a decline in exports and a dampening of inflationary pressure. Moreover, a stronger krona tends to lower the inflation rate, since imported goods and import-competing goods become cheaper. This reinforces the dampening effect on inflation of falling demand. To be able to control for exchange rate channel, we also include the real exchange rate.

\subsection{The lending rate: the bank capital channel}

The bank capital channel describes the impact that various risks have on bank balance sheets and income statements and ultimately on their pricing behaviour and lending. As in Karlsson et al. (2009), it is assumed that banks in Sweden operate on a market characterized by monopolistic competition in which the banks' lending rate is set as a markup on their marginal costs. ${ }^{8}$ The lending rate is therefore influenced by both the interest rate that banks themselves have to pay to borrow funds and the interest rate supplement added by banks when lending on to their customers. The study by Karlsson et al. (2009) indicates that what the macroeconomic literature calls credit spread contains many different components that are affected in one way or another by

\footnotetext{
Footnote 6 continued

for the house price gap and the share price gap and the results indicate that the conclusions of this paper remain intact.

7 A treasury bill is a short-term debt instrument issued by the Swedish National Debt Office. The maturity of these instruments is usually up to one year. Treasury bills are used to finance the government's short-term borrowing requirement.

8 For a more detailed description of the market structure and loan pricing equation, see Arregui et al. (2013), Box 2.
} 
various risks associated with bank operations. Using lending rates together with policy rates in macroeconomic models makes it possible to analyse the effects these risks have on the real economy, besides those stemming from monetary policy. The lending rate that is used as an indicator is a combination of the interest rate that households and firms actually pay on their existing loans. ${ }^{9}$

\subsection{The financial stress index: the uncertainty channel}

The uncertainty channel describes how more uncertainty in financial markets leads to higher precautionary savings and lowers consumption. The degree of uncertainty on financial markets is measured by a "stress index". In line with the arguments presented in Forss Sandahl et al. (2011) and Holmfeldt et al. (2009), an index is constructed that is a composite of developments on four markets: the stock market, the currency market, the money market and the bond market. ${ }^{10}$

\subsubsection{Uncertainty in the stock and currency markets}

There are several ways of measuring disturbances and uncertainty in the stock and currency markets. One of the most important measures is volatility. There is a group of volatility measures that are forward-looking since they are based on option prices (e.g. VIX in the USA). But, from a practical econometric perspective, it is a disadvantage that long time series are not available for these volatility measures. This is why this paper uses the actual volatility in the OMX index, measured as the standard deviation for the OMX index for the previous 30 days. Moreover, the actual volatility of the SEK exchange rate against the euro, measured as the standard deviation for the prices noted for the previous 30 days, is used as a stress indicator for the currency market.

\subsubsection{Uncertainty on the money market}

In the money market, banks extend loans to one another at short maturities to manage day-to-day liquidity needs. The interest rate on this interbank market is called LIBOR (STIBOR in Sweden) and is often compared with the interest rate on treasury bills with corresponding maturities. This interest rate difference, which is called the TED spread, is used as a stress indicator for the money market.

\subsubsection{Uncertainty in the bond market}

The spread in interest rates between mortgage and government bonds, which is called the mortgage spread, says something about how sellers assess the risks associated with each bond. This makes this spread a good indicator of developments on these

\footnotetext{
9 The lending rate is the weighted average of the interest rates for households (2/3) and the interest rate for firms (1/3).

10 Johansson (2013) develop a more complex financial stress index and compare the development of this new financial stress index with a simpler. See also Österholm (2010).
} 
two markets. The mortgage spread is therefore used as a stress indicator for the bond market.

\subsubsection{Financial stress index}

The four indicators are first standardized so that they can be weighted to a composite financial stress index. The weighting is done by giving each indicator the same weight. The resulting index is also standardized which means that the summary financial stress index has a mean of 0 and a standard deviation of 1 by construction, which facilitates interpretation of the index. When the series has a value of zero, it is equal to its historical mean and the stress level should therefore be considered normal. With this standardization, a value of 1 also means that the level of stress is one standard deviation higher than normal.

\section{Methodology and data}

In this section, we present the empirical model that we use to model the interaction between the financial variables described in the previous section and the macroeconomy.

\subsection{The empirical models}

In a prototypical VAR model, the number of parameters is common to be large relative to the number of available observations. Inevitably, this leads to large estimation uncertainty and a risk of overfitting. BVAR models, which combine the data with the researcher's prior beliefs, have proved to be successful tools as informative prior distributions reduce estimation uncertainty while often generating only small biases (Giannone et al. 2015). This approach is often also associated with improved forecasting performance (see, for example, Karlsson 2013 for a review), which makes the BVAR an attractive choice and a standard tool in applied macroeconomics (Bańbura et al. 2010).

The prior distribution in a Bayesian VAR model can be specified in a number of different ways. In this paper, we use the steady-state prior (Villani 2009) as we believe it offers a natural way of incorporating prior beliefs. Additionally, from a forecasting perspective it is appealing to formulate the prior on the unconditional mean (the "steady state") directly, since for increasing forecast horizons the forecasts will converge to the model's estimate of the unconditional mean. Furthermore, the steady-state prior has successfully been used in similar applied research in recent years, e.g. Jarocinski and Smets (2008); Österholm (2010); Clark (2011).

The VAR model can be written on mean-adjusted form as:

$$
\boldsymbol{\Pi}(L)\left(\mathbf{x}_{t}-\boldsymbol{\Psi} \mathbf{d}_{t}\right)=\boldsymbol{\varepsilon}_{t},
$$

where $\boldsymbol{\Pi}(L)=\left(\mathbf{I}-\boldsymbol{\Pi}_{1} L-\cdots-\boldsymbol{\Pi}_{m} L^{m}\right)$ is a lag polynomial of order $m, \mathbf{x}_{t}$ is an $n \times 1$ vector of stationary variables, $\mathbf{d}_{t}$ is a $k \times 1$ vector of deterministic variables, $\boldsymbol{\Psi}$ 
is an $n \times k$ coefficient matrix and $\boldsymbol{\varepsilon}_{t}$ is an $n \times 1$ vector of multivariate normal error terms with mean zero and covariance matrix $\boldsymbol{\Sigma}$. Note that $\boldsymbol{\Psi} \mathbf{d}_{t}$ is the unconditional mean of the process, meaning that priors on $\boldsymbol{\Psi}$ reflect views about the steady states of the variables.

The set of unknown parameters in the model in Eq. (1) is $\boldsymbol{\Theta}=\left\{\boldsymbol{\Psi}, \boldsymbol{\Sigma}, \boldsymbol{\Pi}_{1}, \ldots, \boldsymbol{\Pi}_{m}\right\}$, for which priors must be formulated. As suggested by Villani (2009), the unconditional means in $\boldsymbol{\Psi}$ are assumed to be independent and normally distributed. The specifics of the prior distribution of $\boldsymbol{\Psi}$ in our application are discussed in more detail in Sect. 3.4. For the remaining parameters, $\boldsymbol{\Sigma}$ and $\boldsymbol{\Pi}_{1}, \ldots, \boldsymbol{\Pi}_{m}$, several different priors could in principle be used since $\mathbf{x}_{t}-\boldsymbol{\Psi} \mathbf{d}_{t}$ is a standard VAR given $\boldsymbol{\Psi}$, for which a number of alternatives exist. In this work, we follow common practice among previous studies employing the steady-state prior and use a non-informative prior for the error covariance matrix, $p(\boldsymbol{\Psi}) \propto|\boldsymbol{\Sigma}|^{-\frac{n+1}{2}}$, and a Minnesota prior for the dynamic coefficients in $\boldsymbol{\Pi}_{1}, \ldots, \boldsymbol{\Pi}_{m}$.

The Minnesota prior (Litterman 1979) rests upon the stylized fact that many economic variables behave approximately as random walks. Moreover, coefficients on more distant lags as well as coefficients on variables in equations other than their own are a priori believed to be less important than recent lags and lags of a variable itself. These prior beliefs are incorporated through the use of hyperparameters, which determine the degree of certainty of the beliefs. The dynamic coefficients in $\Pi_{1}, \ldots, \Pi_{m}$ are a priori assumed to be independent and normally distributed with means and standard deviations given by:

$$
\begin{gathered}
E\left[\left(\boldsymbol{\Pi}_{p}\right)_{i, j}\right]= \begin{cases}\delta_{i}, & \text { if } i=j \text { and } p=1, \\
0, & \text { otherwise }\end{cases} \\
\sqrt{V\left[\left(\boldsymbol{\Pi}_{p}\right)_{i, j}\right]}= \begin{cases}\frac{\lambda_{1}}{p^{\lambda_{3}}}, & \text { if } i=j, \\
\frac{\lambda_{1} \lambda_{2} s_{i}}{p^{\lambda_{3}} s_{j}}, & \text { otherwise }\end{cases}
\end{gathered}
$$

Most commonly, the prior mean $\delta_{i}$ in Eq. (2) is set to $\delta_{i}=1$ for all $i$. However, if variable $i$ is believed to be stationary or mean-reverting, $\delta_{i}$ may instead be set to, e.g. 0 or 0.9, as noted by Bańbura et al. (2010) and Karlsson (2013). Equation (3) contains three hyperparameters: $\lambda_{1}>0$ controls the overall tightness, $0<\lambda_{2} \leq 1$ determines the cross-equation shrinkage in the VAR and $\lambda_{3}>0$ governs the lag decay. Larger values of $\lambda_{1}$ will make the prior less informative by increasing the prior variances, whereas smaller values will shrink the coefficients towards the prior means. For the cross-equation tightness $\lambda_{2}$, the upper bound means that lags of other variables in an equation are not subject to additional shrinkage compared to own lags, while smaller values will shrink the VAR model to a collection of AR models. Lastly, high values of $\lambda_{3}$ will reduce the impact of higher-order lags, as opposed to low values which push the model towards making no distinction between recent and distant lags. Together with $s_{i}$, the residual standard deviation from univariate AR(4) models used to scale 
the coefficients, these hyperparameters parametrize the entire prior distribution for the dynamic coefficients.

There are many alternative prior distributions that may be used and for surveys of some of these we refer the reader to Karlsson (2013); Koop and Korobilis (2010). More recently, advances have also been made on important topics such as variable selection and large BVARs. George et al. (2008) developed a stochastic search to selecting restrictions in the BVAR, and Korobilis (2013) proposed an automatic variable selection approach, which Louzis (2015) subsequently applied in conjunction with the steady-state prior. For models of larger dimension, Bańbura et al. (2010) showed that a standard BVAR with a Minnesota-style prior performs well if the overall tightness hyperparameter $\lambda_{1}$ is set in relation to model size.

The hyperparameters parametrizing the Minnesota prior are set in accordance with the literature. Previous studies (e.g. Adolfson et al. 2007; Villani 2009; Österholm 2010) have used an overall tightness of $\lambda_{1}=0.2$, a cross-equation tightness of $\lambda_{2}=$ 0.5 and a lag decay parameter of $\lambda_{3}=1 .{ }^{11}$ As discussed by Villani (2009), the random walk prior of $\delta_{i}=1$ for all $i$ is not consistent with the notion of a steady state. Instead we set $\delta_{i}=0.9$ for variables in levels and $\delta_{i}=0$ for differenced or growth variables. We investigate the sensitivity of the hyperparameters and the prior for $\boldsymbol{\Psi}$ in the sensitivity analysis in Sect. 4.5.

\subsection{Data}

Specification of the model is subject to a trade-off between including all possible variables and, on the other hand, parsimony. Since the degrees of freedom are quickly exhausted when the number of variables and lags increases, a relatively small number of variables is advisable. Too few variables and lags, however, will create problems with omitted variable bias.

Our approach is to start with a small VAR model containing the most important macroeconomic variables. This type of model is often used to analyse different types of shocks (see, for example, Sims 1992; Gerlach and Smets 1995 for early contributions). The original models typically included three variables: a short-term interest rate, the inflation rate and GDP growth. This paper expands on the three-variable model by also including unemployment so as to be able to take account of developments on the labour market. Since Sweden is a small, open economy, the currency rate and foreign GDP growth are also included in the set of variables. ${ }^{12}$ Inflation is calculated based on the core consumer price index (CPIX), which is CPI with households' mortgage costs and direct effects of indirect taxes excluded. Foreign GDP growth is calculated as a $\mathrm{KIX}^{13}$ weighted GDP growth using the 16 most important countries for Sweden.

\footnotetext{
11 Despite the chosen values being standard choices, they are nonetheless arbitrary. An alternative is a hierarchical approach, which is discussed in detail by Giannone et al. (2015). By integrating out the model parameters, we can obtain the likelihood of the data given the hyperparameters, called the marginal likelihood (ML). Maximization of the ML as a function of the hyperparameters is an empirical Bayes strategy with good performance, as demonstrated by the authors.

12 The exchange rate is also included to handle the exchange rate channel.

13 KIX is a weighted effective exchange rate index calculated by the Riksbank.
} 
Table 1 Variables and steady-state priors

\begin{tabular}{|c|c|c|c|c|c|}
\hline \multirow[t]{2}{*}{ Short name } & \multirow[t]{2}{*}{ Series } & \multirow[t]{2}{*}{ Macro-model } & \multirow[t]{2}{*}{ Financial model } & \multicolumn{2}{|c|}{$\underline{\text { Steady-state prior intervals }}{ }^{\mathrm{a}}$} \\
\hline & & & & 1992Q4 and earlier & 1993Q1 and later \\
\hline GDPF & $\begin{array}{l}\mathrm{KIX}^{\mathrm{b}} \text { weighted } \\
\text { foreign real } \\
\text { GDP growth }\end{array}$ & $\mathrm{x}$ & $\mathrm{x}$ & $(0,1)$ & $(0.25,0.75)$ \\
\hline SI & $\begin{array}{l}\text { Financial stress } \\
\text { index }\end{array}$ & & $\mathrm{x}$ & $(-3,3)$ & $(-1,1)$ \\
\hline GDP & $\begin{array}{l}\text { Swedish real } \\
\text { GDP growth }\end{array}$ & $\mathrm{x}$ & $\mathrm{x}$ & $(0.25,0.875)$ & $(0.5,0.625)$ \\
\hline CPIX & $\begin{array}{l}\text { Core consumer } \\
\text { price index } \\
\text { inflation }\end{array}$ & $\mathrm{x}$ & $\mathrm{x}$ & $(0.375,0.9375)$ & $(0.25,0.5625)$ \\
\hline $\mathrm{U}$ & $\begin{array}{l}\text { Unemployment } \\
\text { rate }\end{array}$ & $\mathrm{x}$ & $\mathrm{x}$ & $(4,6)$ & $(5.7,6.7)$ \\
\hline ITB & $\begin{array}{l}\text { Interest on three } \\
\text { month } \\
\text { treasury bills }\end{array}$ & $\mathrm{x}$ & $\mathrm{x}$ & $(5.5,8)$ & $(3,4.5)$ \\
\hline IL & Lending rate & & $\mathrm{x}$ & $(6.5,9)$ & $(4,5.5)$ \\
\hline AGAP & Asset price gap & & $\mathrm{x}$ & $(-4,4)$ & $(-2,2)$ \\
\hline CGAP & Credit gap & & $\mathrm{x}$ & $(-4,4)$ & $(-2,2)$ \\
\hline ER & $\begin{array}{l}\mathrm{KIX}^{\mathrm{b}} \text { (first } \\
\text { difference) }\end{array}$ & $\mathrm{x}$ & $\mathrm{x}$ & $(-3.1,3.1)$ & $(-3,3)$ \\
\hline
\end{tabular}

${ }^{a}$ The steady-state priors are presented as $95 \%$ prior probability intervals for the unconditional means. The underlying distributions are independent normals

${ }^{\mathrm{b}} \mathrm{KIX}$ is a weighted effective exchange rate index calculated by the Riksbank

In a second step, we augment the six-variable macroeconomic model with the four financial variables discussed in the previous section, which we assume summarize the relevant information in the financial sector. For comparative purposes, we will use the model both with and without the financial variables in what we will refer to as the macro- and financial models, respectively. The full list of variables and which variables are included in the models is given in Table 1 . The data are quarterly, ranging from 1989Q1 to 2015Q2, and figures of all variables are shown in Fig. 1. In addition to the macroeconomic and financial variables, the models include a dummy variable for the period 1989Q1-1992Q4 to control for the shift in the Swedish exchange rate regime. In effect, the steady states (unconditional means) of the variables are allowed to shift following 1992Q4.

\subsection{Identification}

Conditional expectations and variance decompositions both make use of orthogonalization of shocks. The orthogonalization is achieved by means of a Cholesky decomposition, which is equivalent to a recursive identification scheme. As a consequence, the ordering of the variables will matter for the final results. Thus, we here 

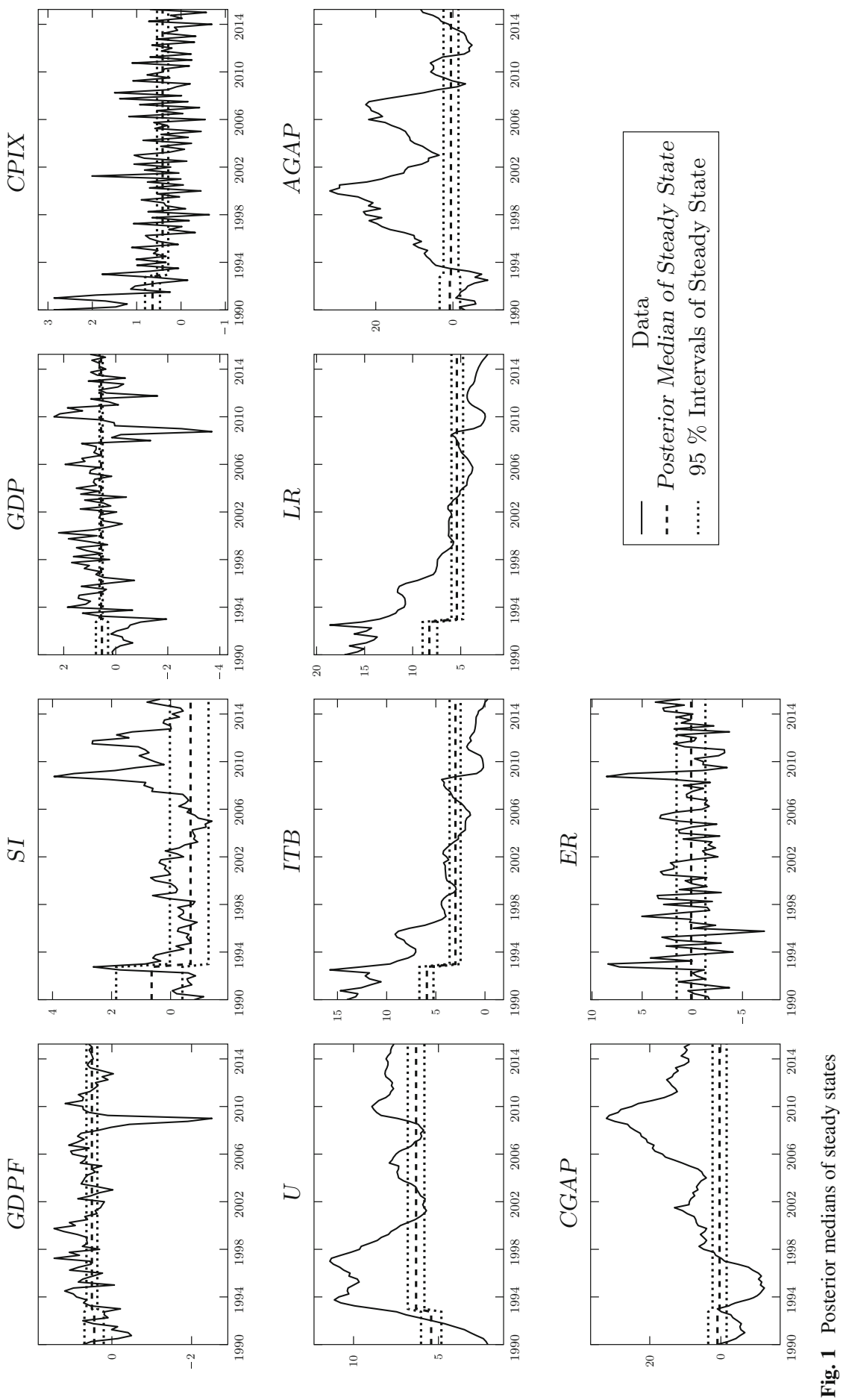
present some motivation for the selected order of variables. While sound, theoretical arguments for the ordering of all of our ten variables are lacking, some guidance can be found in the literature. Hubrich et al. (2013) place foreign variables first followed by output, inflation and interest rates, which is standard practice following Christiano et al. (1999). These macroeconomic variables are followed by financial variables. Christiano et al. (1996) place unemployment after production and inflation but before the federal funds rate. Similarly, Eichenbaum and Evans (1995) place the real exchange rate subsequent to production, inflation and a foreign short-term interest rate spread. Motivated by this, for the macroeconomic variables we select the internal ordering (GDPF, GDP, CPIX, U, ITB, ER). ${ }^{14}$

For the financial variables, there is no clear guidance how to order them. Abildgren (2012), Adalid and Detken (2007) and Hubrich et al. (2013) all agree that the macroeconomic variables, with the exception of the exchange rate, should precede the financial variables. Abildgren (2012) place credit in between share and house prices; in our case, share and house prices are lumped together in the asset price gap and credit is included in the form of the credit gap. Adalid and Detken (2007) place property and equity prices prior to private credit growth, which is only succeeded by the real exchange rate. Moreover, Adalid and Detken (2007) argue that the exchange rate should be placed last. Goodhart and Hofmann (2008) similarly put house prices before credit and Hubrich et al. (2013) estimate all 120 combinations of orderings within their five-variable financial block and conclude that the effect on the results is only minor. This taken together leads us into placing AGAP and CGAP in between ITB and ER.

Holló et al. (2012) and Roye (2014) make the argument that output should come after the financial stress index due to the delay in publication of data, which makes it unreasonable to believe that the financial stress index would react contemporaneously to GDP growth shocks. This argument is made in the context of monthly data, but the issue still remains in quarterly data, albeit in alleviated form. Based on this, our main results are based on an ordering in which SI is placed first among the domestic variables. Finally, the lending rate is placed between ITB and AGAP in order for the lending rate to react contemporaneously to shocks to ITB. This also allows for asset prices and credit to react immediately to lending rate shocks.

To assess the sensitivity to the ordering, alternatives are considered in the sensitivity analysis in Sect. 4.5 as follows: 1) all financial variables, which are regarded as fast moving, are placed after slow-moving macro-variables, 2) all macro-variables are placed after the financial variables and 3) some of the financial variables are placed before the macro-variables and some after.

\subsection{Steady-state intervals}

The priors on the unconditional means, or steady states, are given in Table 1 and are presented as $95 \%$ probability intervals for the variable in question. These choices are similar to the previous literature (see, for example, Österholm 2010; Adolfson et al. 2007) and deviations therefrom are only cosmetic. The Swedish GDP growth is

14 See Table 1 for a key to the abbreviations. 
assumed to have a steady-state value centred on $0.5625 \%$, which corresponds to a yearon-year (YoY) growth rate of $2.25 \%$. The foreign GDP growth is given a wider interval, with its centre being $0.5 \%$. The prior probability interval for inflation is centred on a YoY rate of $1.625 \%$, which is justified by the Riksbank's inflation target of $2 \%$ implying a somewhat lower rate for the CPIX measure. The short-term interest rate has a prior unconditional mean of $3.75 \%$ and the lending rate is given prior intervals which are identical to the short-term interest rates', but one percentage point higher. This roughly constitutes the historical spread between the two. The unemployment is centred on $6.2 \%$ because of the fact that unemployment in Sweden has historically been low but did increase during the global financial crises. The prior for the exchange rate is centred on 0 , with quite wide intervals.

For the stress index, we centre the prior on 0 seeing that this is the mean of the series by construction. The credit gap and the asset price gap are both centred on $0 \%$ as they are both gaps, which in the steady state should be closed. The upper bound is set to $2 \%$, which is motivated by the credit gap being a key indicator for the decision to activate the countercyclical capital buffer and also to decide the level of this buffer. According to the rules the counter cyclical capital buffer will be activated when the credit gap is equal to or higher than $2 \%$. With this in mind, we therefore select $2 \%$ as the upper limit of the prior interval for both credit gap and asset price gap.

As is evident from Fig. 1, there is a mixture of persistent as well as impersistent variables in the model. Theoretically, the persistent variables should be mean-reverting and not drifting off, which goes hand in hand with the idea of steady states. If these variables were truly non-stationary, the steady state may not exist. In the simulation of the posterior distribution, it is, however, possible to obtain draws which imply a non-stationary VAR process, but we enforce the VAR to be stationary by discarding these.

In order to accommodate a belief that the Swedish economy does not affect foreign GDP growth, the latter is treated as block exogenous. This is achieved by using a hyperparameter set to 0.001 that further shrinks the prior variances around zero for parameters relating Swedish variables to the foreign GDP growth.

As a first glance at the results, in Figs. 1 and 2 the medians of the posterior steadystate distributions and the within sample fits, respectively, are plotted. Figure 1 shows the importance of the dummy variable for some of the variables. In Fig. 2, a tendency of better fit for the more persistent variables can be seen. However, it shows that overall the within sample predictions follow the outcomes closely.

\section{Empirical analysis}

This section tries to answer two main questions: (i) Is the financial system important for the development in the real economy? (ii) If it is, what are the characteristics? Section 4.1 presents an evaluation of unconditional forecasts to gauge the general forecasting ability. Section 4.2 addresses the question whether there is any interaction by means of a forecast error variance decomposition. Sections 4.3 and 4.4 discuss recession probabilities and conditional forecasts, respectively, in order to describe the 

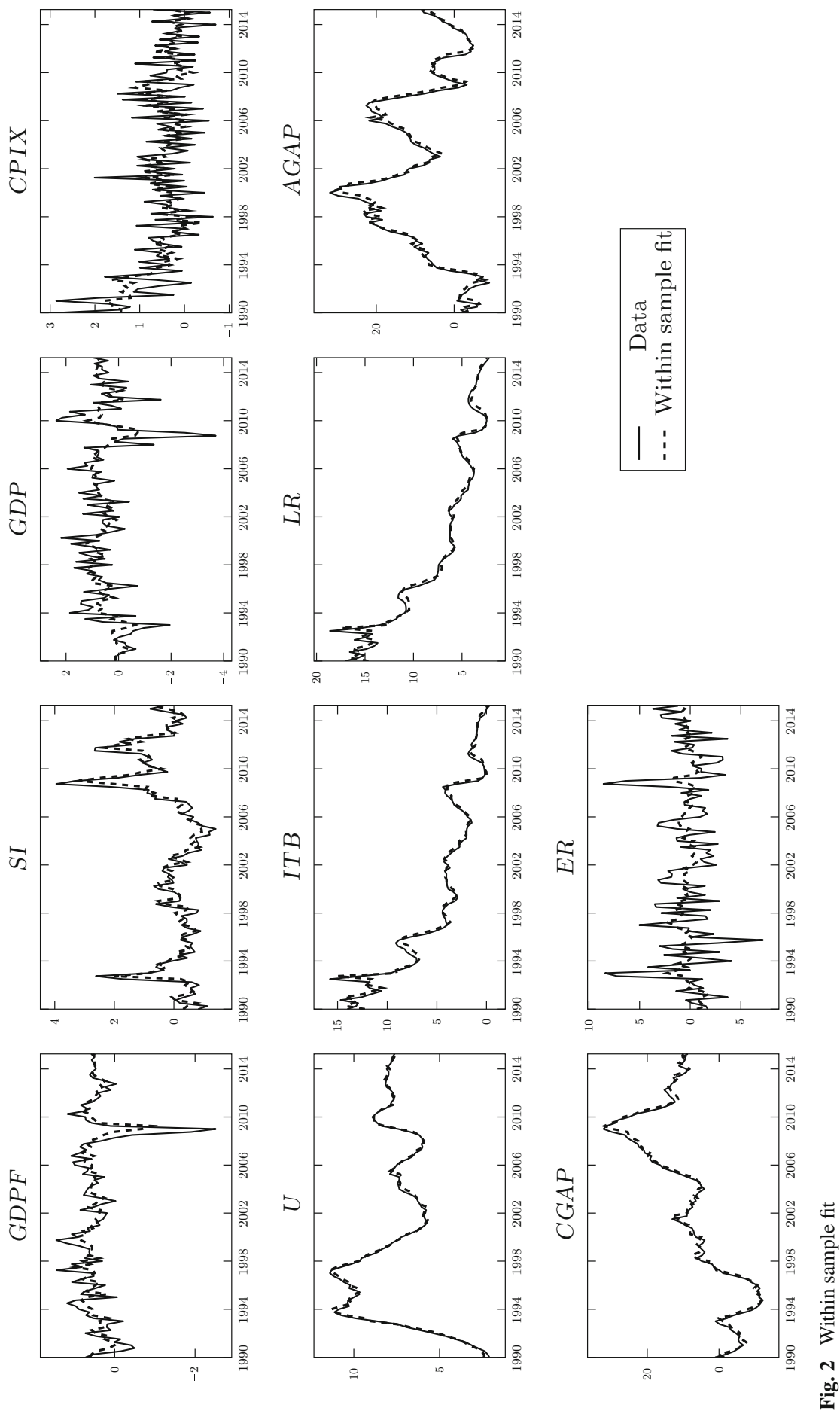
characteristics of the interaction. Finally, a sensitivity analysis of the robustness of the results is presented in Sect. 4.5.

\subsection{Forecast evaluation}

The pseudo-out-of-sample forecast evaluation is conducted with respect to the model's ability to forecast Swedish GDP growth. ${ }^{15}$ For the sake of comparison, we estimate two main models: (i) a macro-model without the financial variables (abbreviated by MAC) and (ii) the main financial model, i.e. the macro-model with four financial variables (referred to as FIN). For a description of the methodology and variables used, see Sect. 3. The evaluation also includes three simpler alternatives for reference. The first is an AR(1) model, the second the most recent observation and the third the mean over the most recent two years.

The out-of-sample forecast evaluation is carried out in the following way. The period 2004Q2 to 2015Q2 is used as the evaluation period and the models make recursive forecasts for these periods. This means that in a first step the models are estimated using data from 1989Q1 to 2004Q1, after which forecasts are made for the next one to eight quarters. In a second step, the models are re-estimated using data from 1989Q1 to 2004Q2 and the forecasts are then redone with the same time horizons as before. ${ }^{16}$ This then continues in the same way moving one quarter ahead at each step. With this procedure each model has at most 45 forecasts (one quarter horizon) down to 38 forecasts (eight quarter horizon), which make up the forecast series that are evaluated. Each model's forecast series is then compared with the actual outcome series and the forecasting abilities of the models are summarized by the root mean squared error (RMSE) with a lower value indicating better forecasting ability. We take the AR(1) model as the main benchmark and divide all other models' RMSE values by the AR(1)'s to obtain RMSE values relative to the benchmark. Thus, in Fig. 3, values below 1 indicate superior forecasting performance relative to the $\mathrm{AR}(1)$.

The results in Fig. 3 show that, in terms of point predictions evaluated by RMSE, there is no major difference between the smaller, basic macro-model and the larger model with financial variables. The figure also includes the RMSE values of these two models, when the forecasts are made conditional on foreign GDP growth. This is done in order to rid the model of possibly predicting badly due to an inability to forecast foreign GDP growth; because of the imposed block exogeneity, the equation for the foreign GDP growth series is essentially just an $\mathrm{AR}(4)$.

The conditional forecasts are improved compared with their unconditional counterparts, even beating the benchmark $\mathrm{AR}(1)$ over all eight quarters. The unconditional forecasts have lower RMSE than the AR(1) for the first three quarters, but for the entire evaluation period the differences are small. Thus, one may conclude that in terms of

\footnotetext{
15 Forecast evaluations with respect to the other variables are available from the authors upon request.

16 In the evaluation, the latest regular outcome figures for the national accounts have been used as the outcome series for Swedish GDP growth. One reason why a real time series has not been used is that the evaluation is not primarily intended to evaluate the absolute forecasting ability of the model including financial variables, but its forecasting ability relative to a model that excludes such variables.
} 


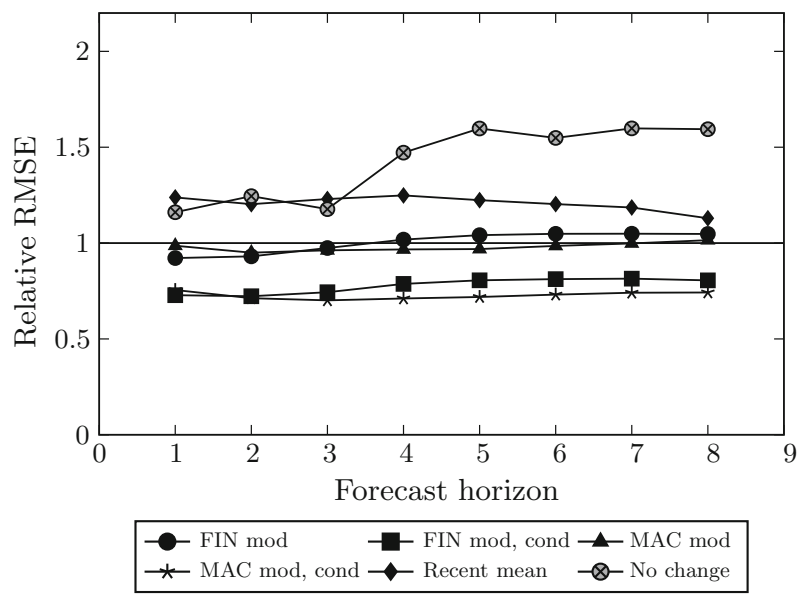

Fig. 3 Root mean squared errors (RMSE) for predictions of Swedish GDP growth relative to AR(1)

forecasting accuracy, there is in essence no difference between the macro-model and the financially augmented model. ${ }^{17}$

The finding in this paper is partly in line with Espinoza et al. (2012). They use different time series models to estimate the importance of financial variables for the real economy and conclude that financial variables contribute to a better prediction of euro area GDP, especially in 1999 and between 2001 and 2003, when using conditional predictive ability tests and a rolling RMSE metric. However, when out-of-sample forecasts are judged under a static RMSE metric, as is done here, they conclude that financial variables do not help in forecasting real activity in the euro area. This is partly because of the assumed identification, in which they isolate the responses of slowmoving variables (the real ones) from that of the fast-moving variables (the financial ones) so that the impulse response associated with shocks to financial variables can be seen as marginal impacts beyond what is already accounted for by the real variables.

\subsection{Variance decomposition-is there any interaction?}

In order to answer our first question, if there is an interaction, we perform a forecast error variance decomposition. Such a procedure estimates how much of the forecast error variance of each of the variables can be explained by exogenous shocks to the other variables. The decomposition is presented in Fig. 4. In order to more clearly see what part can be attributed to the traditional macro-variables and to the financial variables, the variables are combined into three groups: macro-variables, financial variables and Swedish GDP growth. The decomposition of the forecast error variance of Swedish GDP growth, with respect to these groups, is presented in Fig. 5.

\footnotetext{
17 The forecasts have also been evaluated by mean absolute error and bias, which are available upon request. The results and conclusion from these measures are in line with what is presented here. All models have a minor negative bias, but the size, around -0.2 to -0.4 , is similar in size to the AR(1) model's. However, due to the small sample, one or two larger misses have a quite large effect on the bias calculation.
} 


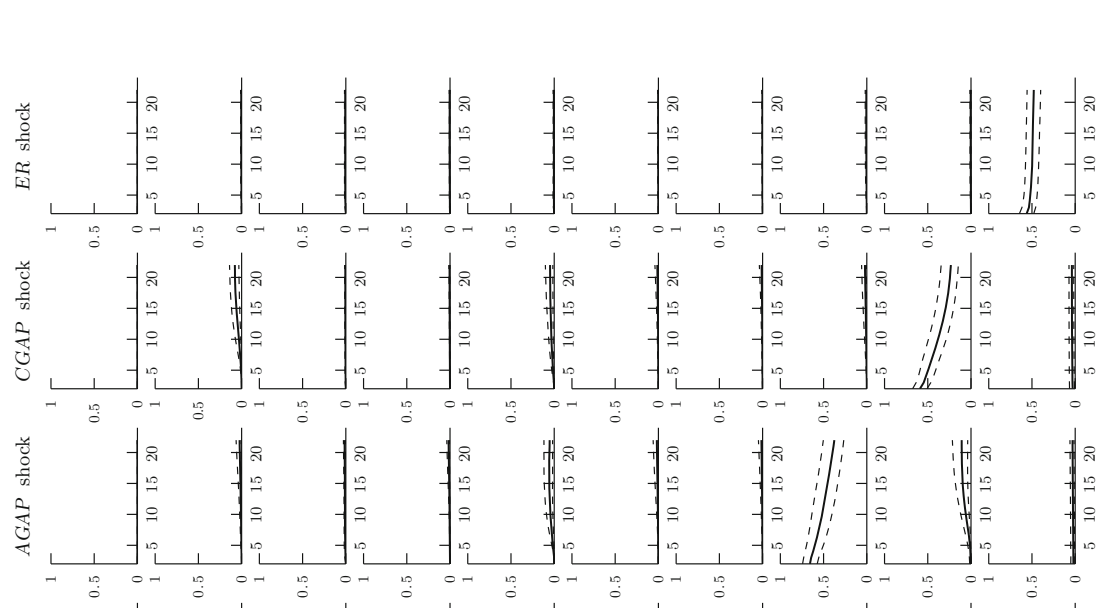

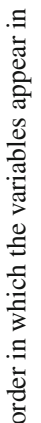
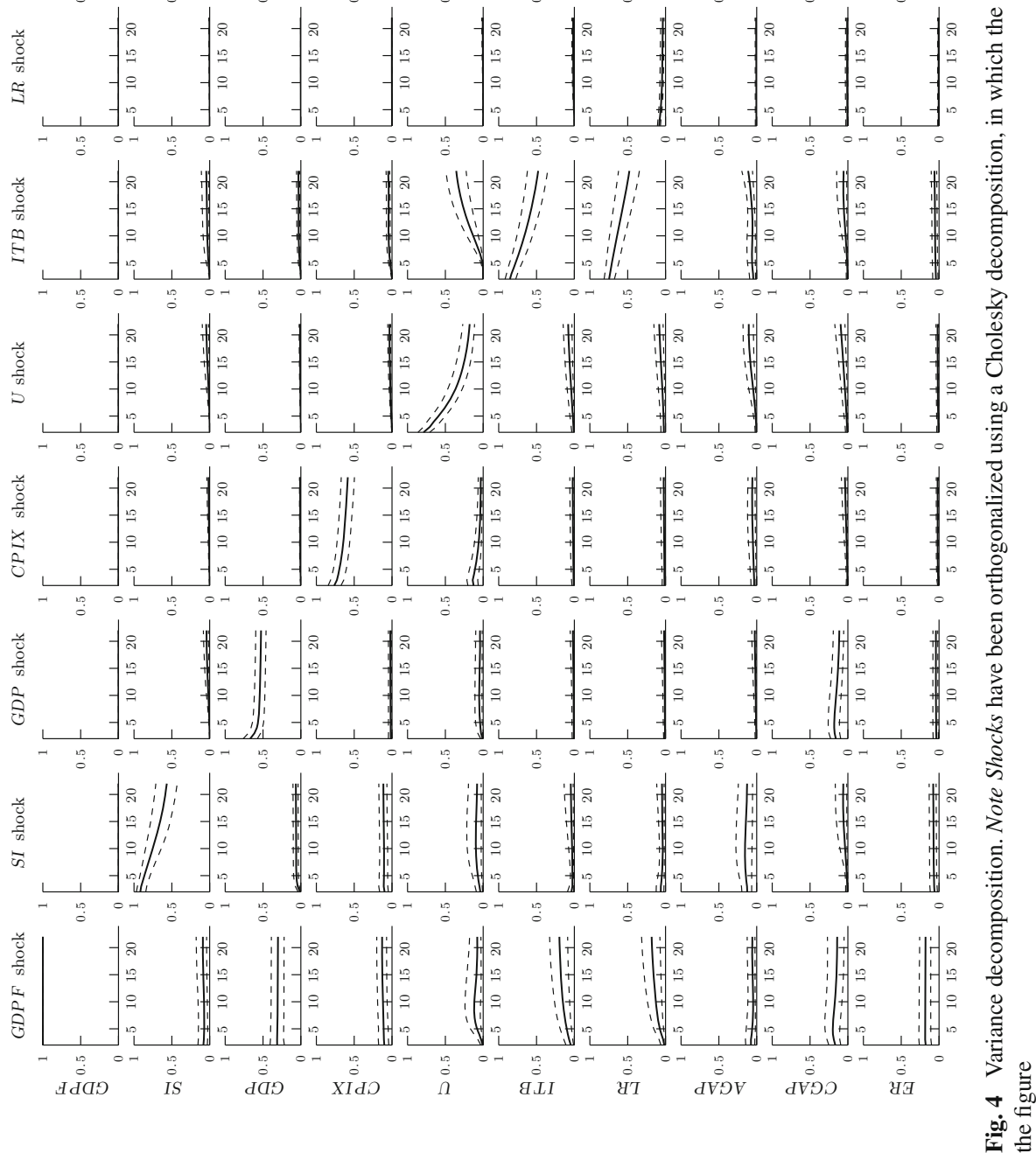


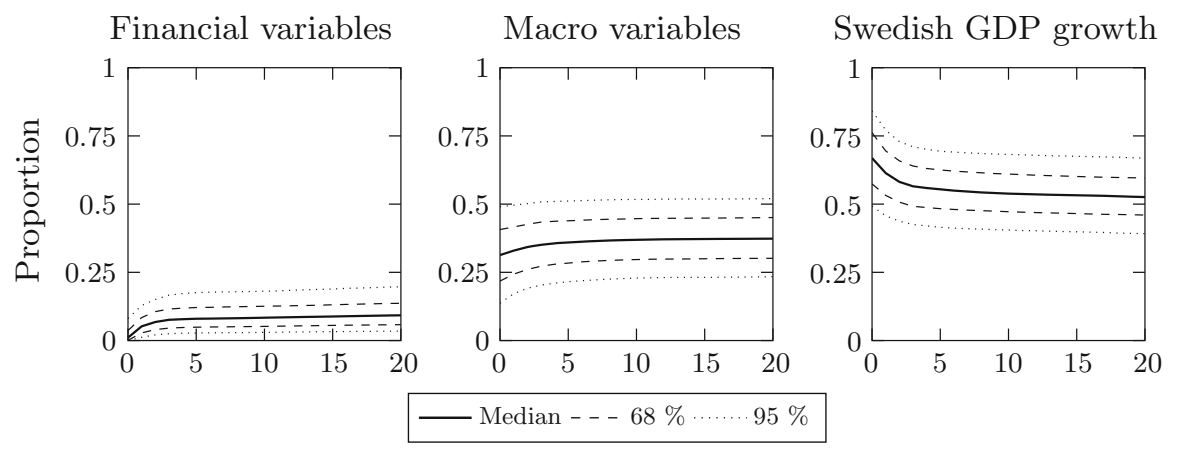

Fig. 5 Median forecast error variance decomposition of GDP with respect to macroeconomic variables, financial indicators and GDP itself

Figure 5 shows that the financial variables are responsible for a non-negligible part of the forecast error variance of Swedish GDP growth: in total, they account for approximately $10 \%$. At around $6 \%$, the stress index accounts for the largest share of the forecast error variance of Swedish GDP growth among the financial variables. Thus, the results suggest that financial variables are important for the real economy, but not immensely so. It shows that it can be important to account for many different aspects of the transmission channels to get a deeper understanding of the macro-financial linkages.

This finding is in line with, but smaller than, the findings of the structural DSGE models such as Christiano et al. (2014) and Jermann and Quadrini (2012). Christiano et al. (2014) study US macroeconomic data over the period 1985-2010 and conclude that the risk shock (the cross-sectional standard deviation of an idiosyncratic productivity shock) accounts for a large share of the fluctuations in GDP and other macroeconomic variables. Jermann and Quadrini (2012) find that financial shocks contributed significantly to the observed dynamics of real and financial variables. More specifically, they find that changes in credit conditions contributed to the downturns in 1990-1991 and 2001 as well as the 2008-2009 recession. Compared to Hubrich et al. (2013), who find a combined effect of five financial shocks on different measures of output to be around 5-45\%, the proportion due to financial variables found here is lower. Similarly, Adolfson et al. (2013) found, using a DSGE model for Sweden, that the shock related to the financial block, which is the entrepreneurial wealth shock in their model, explains about $3 \%$ of the variation in output growth.

As for the reverse relationship, rows 2, 7, 8 and 9 in the third column in Fig. 4 display the share of the forecast error variance of the respective row variables that can be attributed to exogenous shocks to Swedish GDP growth. For the stress index, the lending rate and the asset price gap, Swedish GDP growth appears to be of modest importance. For the credit gap, however, the share attributable to Swedish GDP growth shocks is around $10-15 \%$. Thus, it seems as if the interaction is two-sided. However, it should be emphasized that the model has been constructed with a certain theoretical setting in mind, namely the literature on negative financial externalities and the transmission mechanism. The paper thus sets out to answer a one-sided question, namely 
how the financial system affects the real economy. Although the model seems to indicate that Swedish GDP growth affects the credit gap, the model is not constructed to analyse the determinants of the credit gap or any of the other financial variables for that matter. It should of course not be ruled out that the model could be useful in this sense, but any results in this respect should be interpreted with caution. In the sensitivity analysis in Sect. 4.5, the alternative ordering produces a clear one-sided interaction, which is more in line with the findings in the DSGE literature such as Rabanal and Taheri Sanjani (2015). They show that financial frictions amplified economic fluctuations and the measure of the output gap in all euro countries except France and Germany. On the contrary, in France and Germany financial frictions played a minor role in output gap measures. Financial frictions mattered much more precisely because financial and housing demand shocks are the ones that set the financial accelerator in motion, and those shocks were more important in all euro countries except France and Germany.

To conclude this section, an interaction appears to exist as we find that financial shocks are responsible for approximately $10 \%$ of the forecast error variance decomposition of Swedish GDP growth. The results indicate that a financial stress shock is of particular importance to the real economy. In the opposite direction, a Swedish GDP growth shock appears to be of more importance to the forecast error variance of credit gap than to the forecast error variance of the other financial variables, with an attributable proportion of around $15 \%$. It should again be noted that the ordering of the variables affects the result. The sensitivity analysis in Sect. 4.5 reveals that an alternative ordering alters the conclusion somewhat, although the main conclusion of the existence of a linkage remains intact. Indeed, it is in fact strengthened by the alternative ordering.

\subsection{Recession probabilities-can the interaction help us make better predictions?}

In this subsection, we study the models' implied probabilities of recession. Österholm (2012) performs an alternative forecasting exercise with a steady-state BVAR for the USA. Standing in 2008Q2, the focus of the paper is the model's estimated probability of a coming crisis, with a crisis defined as two consecutive quarters of negative GDP growth. We take the same approach and let the recession probability at time $t$ be defined as the probability of negative Swedish GDP growth at both time $t+1$ and $t+2$. The probability is estimated by computing the proportion of draws in the numerical simulation of the model in which the unconditional forecasts of Swedish GDP growth in $t+1$ and $t+2$ are negative. We calculate the probability over the time period 2004Q1 and 2015Q1 for both the macro- and the financial models. ${ }^{18}$

Before commenting on the results in Fig. 6, it is important to stress that the exercise should not be interpreted as intended to compete with the large literature on early

\footnotetext{
18 We have also generated the model's predicted probability of a coming crisis between 2004Q1 and 2015Q1, with a crisis defined as one quarter of negative growth. The estimated probability is even better when the model only needs to estimate one quarter. These estimates are available upon request.
} 


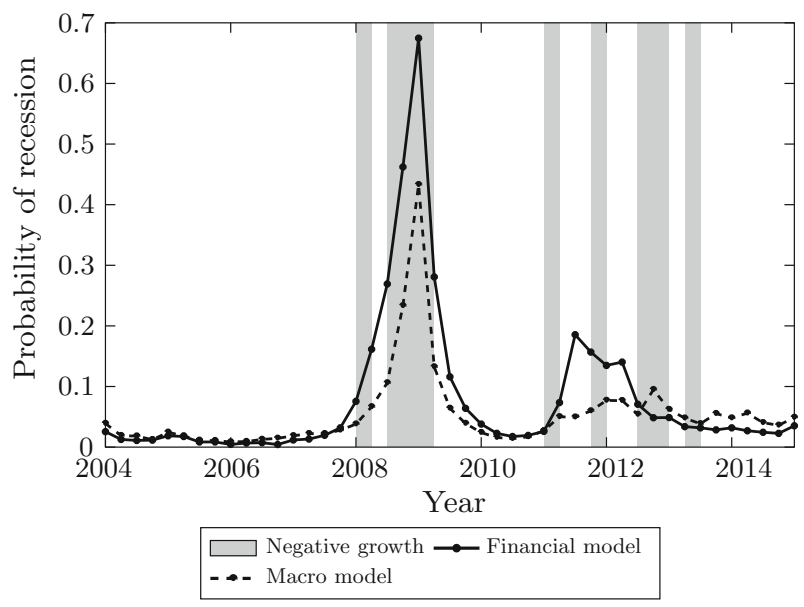

Fig. 6 Future recession probabilities. Note A future recession is defined as negative growth in the next two quarters

warning indicators. ${ }^{19}$ Furthermore, such indicators are usually economic or financial variables or the product of a relatively simple model. Rather, the measure of recession probability in this paper comes from a model trying to incorporate the transmission mechanism within a macro-model. The probability measure is the product of macroand financial developments, interpreted in a reduced form model of the economy. Thus, the relevant benchmark is whether or not the financial model is better at signalling short-term recession risk than is the traditional macro-model.

Beginning in 2007 and ending right before the crisis unfolded in 2008Q3, both models' probabilities of recession steadily increase. The financial model shows a more rapid increase, but up through 2008Q1, the two models' estimated probabilities are more or less the same. However, standing in 2008Q2 — right before Sweden started experiencing negative growth - the financial model's probability of negative growth in both 2008Q3 and 2008Q4 is 16\%, whereas the corresponding estimate from the macro-model is $7 \%$. One could argue that given the lag in response, this indicator would not be an informative leading indicator. However, as mentioned earlier, this indicator produced a clear signal one to two quarters before the global financial crisis hit the Swedish economy.

Beginning in late 2010, the probability of a recession is again slowly increasing following the events leading up to the intensification of the Eurozone crisis, with the European Central Bank reactivating its Securities Markets Program in August 2011. This is directly reflected in the financial model's estimated recession probability, but is at the same time barely visible in the macro-model's because of its lack of financial variables. This indicates that the more complete picture given by the inclusion of financial variables is important, as it provides information about the developments in the financial markets, which are likely to eventually transmit into the real sector.

19 A recent example is López-Salido et al. (2016). 
These findings are also in line with Fornari and Lemke (2010). The authors use a probit regression model linked to a VAR model, a so-called ProbVAR model, to generate conditional recession probabilities and conclude that forecasts can be markedly improved by adding financial variables to this model. It is encouraging that our results agree with Fornari and Lemke (2010) in the sense that financial variables appear to be highly useful and informative. One conclusion from the finding in this paper as well as previous findings is that accounting for financial variables in the episode of a financial crisis enhances model fit and statistical indicators such as probability of recession, compared to the model that does not have a way to systematically account for the financial variables.

One way to complete the recession probability analysis in this paper is to make a careful analysis of the financial variables included in the model. López-Salido et al. (2016) argue that elevated credit market sentiment at year $t-2$ (proxied by the predicted year- $t$ change in the credit spread) is associated with a decline in economic activity in years $t$ through $t+2 .{ }^{20}$ That is, when their sentiment proxies indicate that credit risk is aggressively priced, this tends to be followed by a subsequent widening of credit spreads, and the timing of this widening is, in turn, closely tied to the onset of a contraction in economic activity. One way to further develop the model in this paper is to include the credit market sentiment in financial stress index instead of TED spread and mortgage bond spread. ${ }^{21}$ This is left as a suggestion for future research.

\subsection{Conditional forecasts - can the interaction improve our estimates of crisis effects?}

Another way of analysing whether there is any potential gain of including financial variables in the model is by conditioning on them to investigate how the forecasts change had we known their developments. In particular, it is illustrative to make forecasts before the crisis fully developed and compare the predictions from the financial model, conditional upon the financial variables, with the macro-model's predictions. If the model is reasonably constructed, it should to some degree signal that times are worsening if we condition upon the financial development during the crisis. The conditional forecasts in this subsection are reminiscent of the conditional predictions in Bańbura et al. (2015) and Espinoza et al. (2012). As also pointed out by these authors, in the current setup conditional forecasts are created by shocking the system in such a way that the conditioning path is satisfied, which imposes restrictions on the errors. Contrary to Bańbura et al. (2015), shocks are produced in a structural representation of the model and then transformed to the reduced form. ${ }^{22}$ For this reason, the ordering

\footnotetext{
20 The credit spread is measured by the spread between yields on seasoned long-term Baa-rated industrial bond and yields on comparable-maturity Treasury securities.

21 Another way to do this is to divide the financial stress index to two different stress indices: one that capture the volatility at the stock and currency markets and one that captures the spreads in the money and bond market. In that case, the spread for the bond market can be replaced by the credit market sentiment.

22 The method is similar to that used by Adolfson et al. (2005). More specifically, the procedure at forecast horizon $h$ is as follows: 1) shocks for the macroeconomic variables are drawn from their estimated distri-
} 


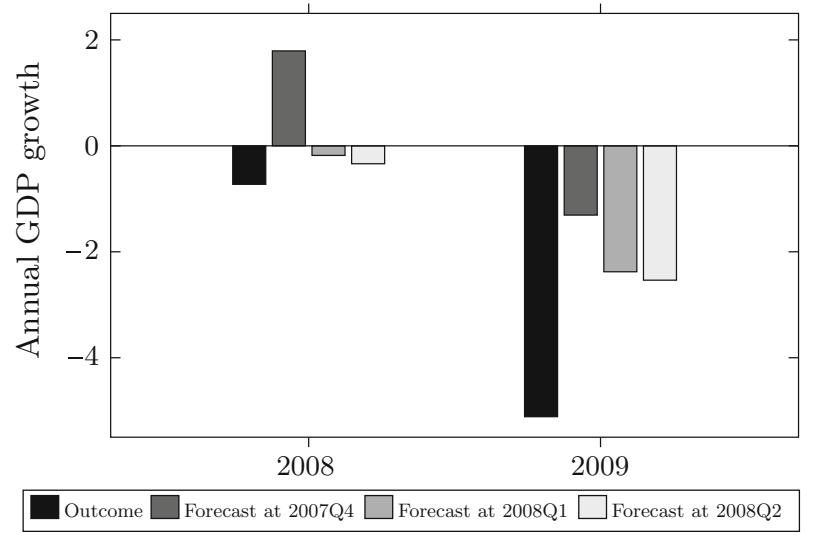

Fig. 7 Financial model's forecasts of annual GDP growth in 2008 and 2009. Note The forecasts are made conditional upon the financial indicators and foreign GDP growth during 2008 and 2009

of the variables will affect the results as the transformations are based on a recursive identification scheme.

This hypothetical exercise is carried out as follows. The two models are estimated using data up to and including 2007Q4. Both models make out-of-sample conditional forecasts of Swedish GDP growth in 2008 and 2009 by transforming the quarterly forecasts to annual growth. The financial model's forecasts are conditional on the outcomes of foreign GDP growth and the four financial variables in 2008Q1-2009Q4 and the macro-model's forecasts are conditional on the outcome of foreign GDP growth throughout the same period. Next, data for 2008Q1 are added to the estimation sample and the out-of-sample conditional forecasting repeated (conditional on outcomes in 2008Q2-2009Q4). Lastly, the same task is repeated a third time using also data for 2008Q2 in the estimation (with forecasts conditional on outcomes in 2008Q32009Q4). Thus, the exercise results in three forecasts for 2008 and three forecasts for 2009 for each model, with each forecast triple containing forecasts using increasing amounts of information in the estimation.

Figures 7 and 8 display the financial and macro-models' predictions for annual growth in 2008 and 2009, respectively. As expected, the financial model provides forecasts that are more in line with the outcomes. In Fig. 7, for the model estimated at 2007Q4 the negative growth in 2008 is not anticipated, but a downturn in 2009 is predicted, although not the full size of it. Estimating the model at 2008Q1 and 2008Q2 gives more pessimistic forecasts that are closer to the outcome. This should be contrasted to Fig. 8 and the macro-model's predictions. The pattern of more pessimistic predictions as the estimation sample is increased persists, but they are markedly more optimistic at around $-1.5 \%$ than the financial model's at around $-3 \%$. A difference of 1.5 percentage points might at a first glance seem small, but could be viewed in light of the small differences in unconditional forecasts (see Table 2). Another way of

butions, 2) a shock to foreign GDP growth is injected such that it satisfies its condition and 3) given the previous shocks, financial shocks are drawn to make the financial variables meet their conditions. 


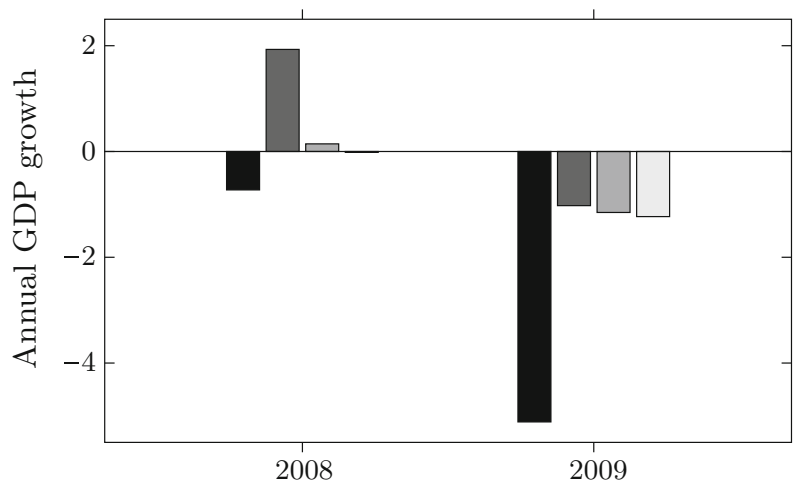

Outcome $\square$ Forecast at 2007Q4 $\square$ Forecast at 2008Q1 $\square$ Forecast at 2008Q2

Fig. 8 Macro-model's forecasts of annual GDP growth in 2008 and 2009. Note The forecasts are made conditional upon foreign GDP growth during 2008 and 2009

describing the $1.5 \%$ point difference is to relate it to the long-run average of Swedish GDP growth, which stands at approximately $2 \%$ for the sample used in this paper (1989Q1 to 2015Q2). Yet another is to relate the 1.5 percentage point difference to the standard deviation of the series, which is 0.93 . Summing up, the financial model's prediction of Swedish GDP growth in this exercise seems to be better compared to the macro-model's forecast. ${ }^{23}$

These forecasts illustrate what is perhaps the greatest advantage of augmenting a traditional macro-model with financial variables. With the financial model, it is possible to carry out forecasts that are conditional on developments in the financial system, an exercise that is of particular interest when these exhibit increased volatility.

As discussed in the identification section (Sect. 3.3), these forecasts are dependent upon the ordering of the variables. For this reason, in the sensitivity analysis (see Sect. 4.5) we consider an alternative ordering and redo the preceding forecasting exercise.

The conditional forecast exercise in this subsection is generally in line with the findings in IMF (2015), Bańbura et al. (2015) and Espinoza et al. (2012). IMF (2015) analyse how balance sheets of households and non-financial corporations affect the economic outlook using a BVAR model. They find that using balance sheet information improves the forecast of aggregate activity when applied to the USA. In addition, shocks to balance sheets are also found to have a significant and differentiated economic impact, suggesting that balance sheets carry additional information. Bańbura et al. (2015) also use a BVAR model, as well as a large dynamic factor model, to estimate the interaction between 26 euro area macroeconomic and financial variables. They find that the two approaches generally deliver similar forecasts and scenario

\footnotetext{
23 While the median forecast may be close to the realization, it may be associated with large uncertainties. For this reason, we have also compared prediction intervals from the models. The financial model's prediction intervals are generally wider, but only by $5-15 \%$. The complete results are available from the authors upon request.
} 
assessments. Their conditional forecast exercise is similar to ours, but instead they condition on real GDP, consumer prices and short-term interest rates. Interestingly, the forecasts are generally in line with the outcomes, with the exception of loans to households and firms where the major downturn is not fully anticipated. In our case, the situation is the opposite since we condition upon the financial variables to make improved forecasts of the growth of GDP. Espinoza et al. (2012) find similar, improved results when forecasting ability is assessed as if in real time. In their base line model, however, financial variables does not provide any extra information to their model where euro area GDP growth is explained by the USA and Rest of the World GDP growth. In short, the literature on conditional forecasts seems to find some evidence of a two-way macro-financial linkage, although the amount of research still is too limited to allow for any strong conclusions in this respect.

\subsection{Sensitivity analysis}

We investigate the robustness of the results by conducting a sensitivity analysis. This is done in two parts. In the first part, the specifications in the prior are changed one by one, changing the ordering of the variables and also considering the Minnesota prior (i.e. without an informative prior on the steady state). We check the robustness by studying how future forecasts and the forecast error variance decompositions after 20 periods change. In the second part, we select one alternative ordering and rerun the analysis in full with the alternative ordering to investigate the sensitivity of the results to our particular choice.

The first part includes changing the hyperparameters $\lambda_{1}, \lambda_{2}$ and $\lambda_{3}$, relocating the centre of the prior probability intervals for the steady states and also extending the width of the prior intervals for the steady states. All changes are done one by one. Finally, we elaborate with alternative identification assumptions, where the financial variables are added after the macro-variables, to see how important the identification assumption is for the results.

The first two hyperparameters $\lambda_{1}$ and $\lambda_{2}$ are increased so as to relax the informativeness of the prior. The lag decay parameter, $\lambda_{3}$, is also increased, but this has the opposite effect of a tighter prior. For the steady-state priors, we consider two types of changes. First, we let all prior probability intervals keep their length, but shift their centre upwards by one standard deviation. Second, the prior probability intervals remain centred on the same values, but the length of the intervals is doubled. These two changes will give us some idea of how the results are affected by the location and the tightness of the steady-state priors. We also investigate sensitivity with respect to the ordering of the variables. Three alternative orderings are considered, in which 1) the financial stress index is moved to the second-to-last position, 2) most of the financial variables come first and Swedish GDP growth is last and 3) asset price gap and credit gap are moved to come prior to the stress index. By doing this, the hope is to gain an understanding of how important the ordering actually is. The results are displayed in Table 2 .

Table 2 suggests that with respect to the choices for the prior, the results seem to be insensitive. The future forecasts and the forecast error variance decompositions 
Table 2 Sensitivity analysis

\begin{tabular}{|c|c|c|c|c|c|c|c|c|}
\hline \multirow[t]{2}{*}{ Prior changed } & \multicolumn{5}{|c|}{ Forecasts of annual GDP growth } & \multicolumn{3}{|c|}{ FEVD of GDP, 20 periods } \\
\hline & 2015 & 2016 & 2017 & 2018 & 2019 & Macro & Financial & GDP \\
\hline Baseline & 2.97 & 3.34 & 2.90 & 2.59 & 2.33 & 0.37 & 0.10 & 0.53 \\
\hline$\lambda_{1}$ & 3.06 & 3.46 & 2.82 & 2.53 & 2.33 & 0.45 & 0.14 & 0.41 \\
\hline$\lambda_{2}$ & 3.03 & 3.38 & 2.84 & 2.57 & 2.35 & 0.43 & 0.13 & 0.44 \\
\hline$\lambda_{3}$ & 2.94 & 3.30 & 2.94 & 2.63 & 2.37 & 0.35 & 0.08 & 0.57 \\
\hline GDPF Mean & 2.98 & 3.33 & 2.87 & 2.62 & 2.36 & 0.37 & 0.10 & 0.53 \\
\hline CGAP Mean & 2.96 & 3.32 & 2.91 & 2.62 & 2.39 & 0.37 & 0.10 & 0.53 \\
\hline AGAP Mean & 2.98 & 3.32 & 2.87 & 2.56 & 2.33 & 0.37 & 0.10 & 0.53 \\
\hline LR Mean & 2.98 & 3.33 & 2.87 & 2.61 & 2.35 & 0.37 & 0.10 & 0.53 \\
\hline SI Mean & 2.97 & 3.31 & 2.83 & 2.51 & 2.26 & 0.38 & 0.10 & 0.53 \\
\hline ITB Mean & 2.98 & 3.30 & 2.84 & 2.56 & 2.32 & 0.37 & 0.10 & 0.53 \\
\hline ER Mean & 2.99 & 3.37 & 2.92 & 2.61 & 2.33 & 0.37 & 0.10 & 0.53 \\
\hline CPIX Mean & 2.97 & 3.36 & 2.90 & 2.61 & 2.35 & 0.37 & 0.10 & 0.53 \\
\hline UNEMP Mean & 2.98 & 3.36 & 2.91 & 2.61 & 2.36 & 0.37 & 0.10 & 0.53 \\
\hline GDP Mean & 2.97 & 3.33 & 2.88 & 2.58 & 2.33 & 0.37 & 0.10 & 0.53 \\
\hline GDPF SD & 2.98 & 3.38 & 2.95 & 2.61 & 2.35 & 0.38 & 0.10 & 0.52 \\
\hline CGAP SD & 3.01 & 3.41 & 2.87 & 2.56 & 2.32 & 0.38 & 0.10 & 0.53 \\
\hline AGAP SD & 3.01 & 3.52 & 3.11 & 2.84 & 2.59 & 0.37 & 0.10 & 0.53 \\
\hline LR SD & 2.97 & 3.37 & 2.93 & 2.61 & 2.34 & 0.37 & 0.10 & 0.53 \\
\hline SI SD & 2.97 & 3.27 & 2.78 & 2.47 & 2.24 & 0.37 & 0.10 & 0.53 \\
\hline ITB SD & 2.98 & 3.42 & 2.98 & 2.66 & 2.34 & 0.38 & 0.10 & 0.52 \\
\hline ER SD & 2.99 & 3.38 & 2.92 & 2.61 & 2.35 & 0.37 & 0.10 & 0.53 \\
\hline CPIX SD & 2.97 & 3.34 & 2.93 & 2.62 & 2.40 & 0.37 & 0.10 & 0.53 \\
\hline UNEMP SD & 2.98 & 3.36 & 2.93 & 2.60 & 2.32 & 0.37 & 0.10 & 0.53 \\
\hline GDP SD & 2.98 & 3.32 & 2.85 & 2.55 & 2.32 & 0.37 & 0.10 & 0.53 \\
\hline Order 1 & 2.98 & 3.35 & 2.87 & 2.61 & 2.36 & 0.39 & 0.07 & 0.54 \\
\hline Order 2 & 2.98 & 3.34 & 2.86 & 2.58 & 2.33 & 0.38 & 0.25 & 0.37 \\
\hline Order 3 & 2.98 & 3.37 & 2.88 & 2.57 & 2.30 & 0.36 & 0.22 & 0.42 \\
\hline Minnesota & 2.90 & 3.00 & 2.65 & 2.56 & 2.55 & 0.36 & 0.10 & 0.54 \\
\hline
\end{tabular}

The hyperparameters $\lambda_{1}, \lambda_{2}$ and $\lambda_{3}$ are changed to $0.5,1$ and 2, respectively. The "Mean" row entires are subject to a one standard deviation upward shift of the mean of the prior. The "SD" row entries are subject to a doubling of the prior $95 \%$ probability interval. At the end of the table, the ordering of the variables is reshuffled. Order 1 is (GDPF, GDP, CPIX, U, ITB, IL, AGAP, CGAP, SI, ER), Order 2 is (GDPF, CGAP, AGAP, IL, ITB, SI, ER, CPIX, U, GDP) and Order 3 is (GDPF, AGAP, CGAP, SI, GDP, CPIX, U, ITB, IL, ER). Lastly, the model is estimated with the Minnesota prior instead of the steady-state prior. The first block of columns displays the annual forecasts of GDP growth of the coming years. The second block displays the proportion of the forecast error variance decomposition of GDP 20 periods ahead, which is attributable to the macroeconomic variables, the financial variables and Swedish GDP growth itself, respectively 
are all similar when we change the hyperparameters and the centre and lengths of the prior probability intervals. Using the alternative orderings does not affect the future forecasts, as expected. When using the first alternative ordering of variables, i.e. when the stress index is moved, also the forecast error variance decompositions remain close to the main results. However, when considering the second or third alternative ordering, the contribution to the forecast error variances which is due to financial shocks increases from 10 to 22 and $25 \%$, respectively. By the nature of the new orderings, this is hardly surprising; both of them place financial variables (other than just the stress index) prior to Swedish GDP growth. As discussed in, for example, Eichenbaum and Evans (1995), this means that we are implicitly assuming that the preceding financial variables are causally prior to it. In our main ordering, only the stress index is assumed to be causally prior to Swedish GDP growth. For this reason, the second and third orderings illustrate the fact that as more financial variables are assumed to be causally prior to it, the share of forecast error variances attributable to these variables increases. Using the Minnesota prior leaves the forecast error variance decompositions virtually unchanged, but the trajectory of the future forecast is somewhat flatter.

In the second part of our sensitivity analysis, we redo the entire statistical analysis with a new ordering. However, since most of the results are not dependent on the ordering, only the parts which change, i.e. the conditional forecast exercise and the forecast error variance decompositions, are presented here.

The alternative ordering considered is based on moving the asset price and credit gaps from positions 8 and 9 to positions 2 and 3, i.e. placing them first among the domestic variables. There are two main reasons for doing so. The results are most sensitive to moving variables in the conditioning to positions before Swedish GDP growth. Thus, if the results change, the induced change will likely be among the larger changes that can occur by simply reordering the variables. Additionally, the consequence of this reordering in a recursive setting is that the two gap series will only react to all other domestic variables with a lag. Given their persistent nature, such a slow reaction is sensible.

Since the internal ordering of the macro-variables is unchanged, the macro-model's forecasts are also unchanged and therefore not displayed here (instead, see Fig. 8). The results of the conditional forecasts with the alternative ordering are displayed in Fig. 9.

As seen in Fig. 9, the effect of changing the order of the variables is substantial. The forecast of annual Swedish GDP growth in 2009 made in 2007Q4 is almost 2 percentage points lower than with the main ordering (see Fig. 7). Overall, the model seems to be more responsive to the signals in the financial variables. This result has a number of implications. First, it means that the ordering is a non-trivial task, which affects the end result. Second, it implies that not only the choice of included variables is important for the model's performance, but also the (explicitly or implicitly) assumed interactions, which hardly is surprising. However, it does not necessarily constitute a problem. With a more elaborate and careful identification strategy, with identification being a main focus rather than a necessary by-product of the analysis, one could possibly obtain an even better performance of the model. This is also the case for the steady-state priors. From time to time, structural changes may change the steady-state 


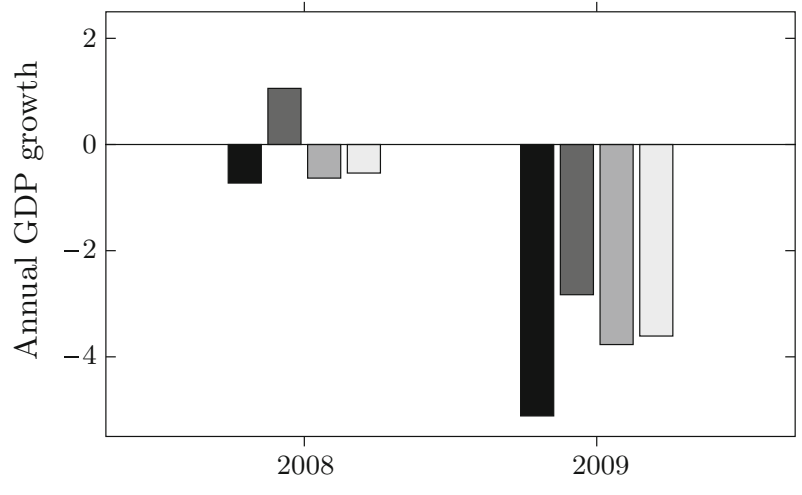

Outcome $\square$ Forecast at 2007Q4 $\square$ Forecast at 2008Q1 $\square$ Forecast at 2008Q2

Fig. 9 Financial model's forecasts of annual GDP growth in 2008 and 2009. Note The forecasts are made conditional upon the financial indicators and foreign GDP growth during 2008 and 2009, but with a different ordering than in Fig. 4

assumptions given as priors in Table 1 . With more elaborate and carefully chosen prior beliefs, one could possibly obtain even better performance of the model because of the structural changes. ${ }^{24}$ Furthermore, it would be highly interesting to incorporate nonlinearities in this context as well. It is plausible that the relationships are not constant over time, as implicitly assumed here, but change. For example, if the conditioning paths in some sense suggest crisis times, the model itself may need to change. To some extent, this is achieved here by changing the ordering of the variables. This could then suggest that different identifications may be useful at different times. Such nonlinear macro-financial linkages are discussed in detail by Hubrich et al. (2013). ${ }^{25}$ However, Fornari and Stracca (2013) provide some evidence of the non-linearities being absent by estimating their model with and without crisis times and noting that the results are fairly stable.

\section{Conclusion and comments}

The purpose of this paper has been to answer two main questions: (i) Is the financial system important for the development in the real economy? (ii) If it is, what are the characteristics? After estimating a BVAR model for the macroeconomy, augmented with financial variables representing the transmission mechanism, a decomposition of the forecast error variance of Swedish GDP growth reveals that the financial shocks explain $10-25 \%$ of the variance, depending on the chosen identification. As might be expected, an ordering where the financial variables come first generates the higher forecast error variance.

\footnotetext{
24 Fornari and Stracca (2013), for example, consider sign restrictions as in Rubio-Ramírez et al. (2010). A similar approach could be taken here.

25 In addition, such an identification pursuit and steady-state prior choices could also possibly mitigate the relevance of the Lucas' critique.
} 
To see the characteristics of the financial-to-real interaction, two different approaches were used. First, financial variables were included to see whether this improved the model's ability to estimate recession probabilities and second, conditional forecasts were used to quantify the effects on Swedish GDP growth of a financial crisis. The results indicate that the financial model, to a larger extent than the macroeconomic model, acknowledges the increasing distress preceding the crisis. The financial model's estimated probability of a recession is stronger at an earlier date than the macroeconomic model's, thus connecting the financial turmoil to greater uncertainty surrounding the growth of the economy. Second, and more importantly, the financial model produces a more accurate forecast of the depth of the 2008-2009 crisis in Sweden, when comparing forecasts made in the quarters just before the outbreak of the crisis. Conditional on the financial variables, the model's forecast of Swedish GDP growth over the coming two years is clearly lower-and thus more accurate-than the macro-model's forecast. In the alternative ordering of variables tried in the sensitivity analysis, the advantage of conditioning on the financial variables is further accentuated.

Furthermore, this increase in explanatory power does not come at the expense of lower predictive power. There is no loss to point predictions, in terms of root mean squared error (RMSE), by expanding a traditional macroeconomic model with financial variables. Compared with the traditional macroeconomic model, there is no difference as to their unconditional forecasting performances.

Concluding, the proposed macro-financial model fills a gap in the literature by providing an empirical model that can be used to analyse and forecast the impact that development of the financial sector may have on the real economy.

For future research, there are many interesting extensions one could make. The inclusion of stochastic volatility in the steady-state prior, as proposed by Clark (2011), appears to be a promising alternative. Similarly, allowing the model to have timevarying or regime-switching parameters could be interesting ways of incorporating non-linearities, which might improve the model even further.

Acknowledgements We would like to thank Thomas Bergman, Per Englund, Torbjörn Halldin and Martin Solberger and the seminar participants at the Ministry of Finance and the Department of Statistics at Uppsala University, three anonymous referees, and two editors for useful suggestions and discussions. A special thanks to John Hassler, Pehr Wissén, Lars E O Svensson, Peter Englund, Mats Kinnwall, Lars Hörngren, Johan Lyhagen, Fredrik Bystedt, Albin Kainelainen and Robert Boije for valuable comments on an earlier draft of the paper and to Mattias Villani for allowing us to use his code. The views expressed in this paper are solely the responsibility of the authors and should not necessarily be taken to reflect the views of the Swedish National Debt Office and the Ministry of Finance.

Open Access This article is distributed under the terms of the Creative Commons Attribution 4.0 International License (http://creativecommons.org/licenses/by/4.0/), which permits unrestricted use, distribution, and reproduction in any medium, provided you give appropriate credit to the original author(s) and the source, provide a link to the Creative Commons license, and indicate if changes were made. 


\section{Appendix: The theoretical effects of the financial system on the real economy}

We start by giving a detailed description of the way negative external effects cause the accumulation and liquidation of financial imbalances. Next, we present a comprehensive but tractable description of the transmission mechanism and its channels. Finally, we describe the way the identified negative externalities affect the real economy through the different transmission channels

\section{Negative externalities and financial imbalances}

The importance of the financial shocks and financial frictions is well summarized in Brunnermeier et al. (2012). They point out that external funding is typically more expensive than internal funding through retained earnings. This implies that agents to a large extent issue claims in the form of debt which comes with some severe drawbacks: an adverse shock wipes out large fraction of the levered borrowers net worth, limiting his risk bearing capacity in the future. Hence, a temporary adverse shock is very persistent since it can take a long time until agents can rebuild their net worth through retained earnings. Besides persistence, an initial shock is amplified if agents are forced to resell their capital. Since resales depress the price of capital, the net worth of agents suffers even further (loss spiral). In addition, margins and haircuts might rise (loan-to-value ratios might fall) forcing agents to lower their leverage ratio (margin spiral).

The persistence of a temporary shock lowers future asset prices, which in turn feed back to lower contemporaneous asset prices, eroding productive agents' net worth even further and leading to more resales which can lead to rich volatility dynamics and explain the inherent stability of the financial system. Because of these mechanisms, credit risk can be dwarfed by liquidity risk and cause a large discontinuous drop in the price level and a dry-up of funding.

The role of financial institutions is to mitigate some of these financial frictions. However, by investing in long-term projects and by issuing short-term debt claims, financial institutions expose themselves to a liquidity mismatch, which can result in fragility. Banks can also ensure that the borrower of funds exerts enough effort such that loans can be repaid. Moreover, Banks can also create securities and offer deposit contracts. However, by doing so, they expose themselves to bank runs. Financial intermediaries are thus key in understanding the interaction between financial system and real economy. Brunnermeier et al. (2012), Shin (2010) and Hanson et al. (2011), among others, argue that financial institutions do not take adequate account of the contagion effects of their behaviour on the financial system and the real economy.

Predatory pricing of risk, herd behaviour and the moral hazard in combination with the implicit safety net may over time lead to financial imbalances. A correction of these imbalances propagates rapidly through the financial system because of the linkages that exist between the various financial institutions. Fire sale is another negative externality that leads to asset prices fall even more and affect other institutions with similar assets (e.g. Kashyap et al. 2011). In addition, financial institutions have much more 


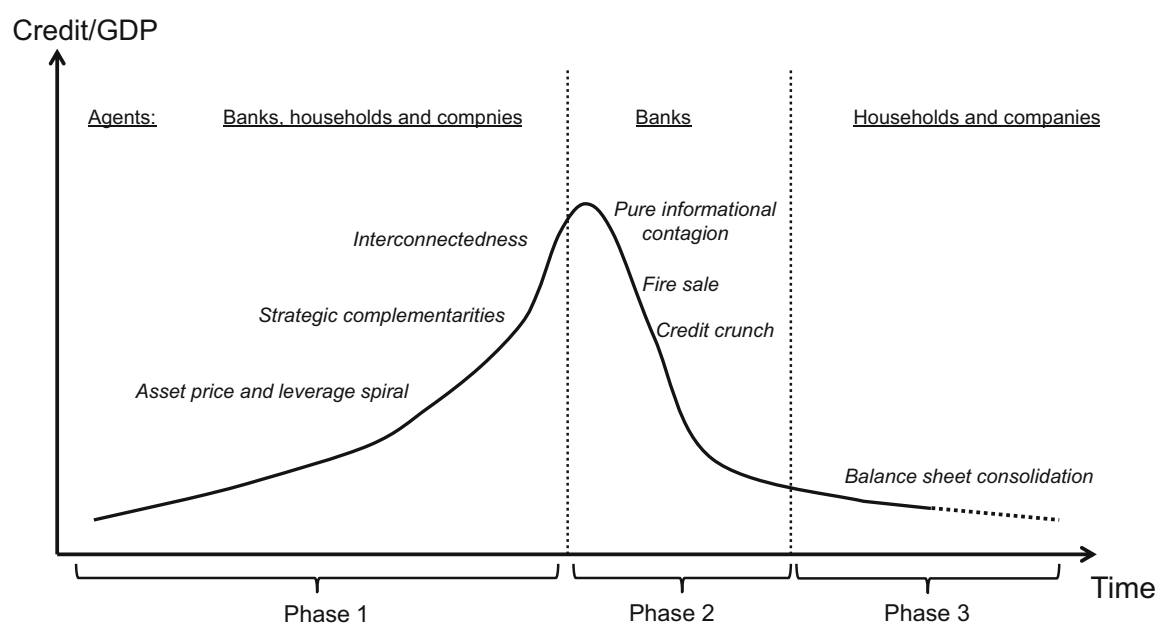

Fig. 10 Most important negative external effects in a stylized credit cycle

difficulties to roll over their short-term interbank funding (Perotti and Suarez 2009). What matters in the end is perhaps not the boom or the asset price bubble in itself, but rather whether the boom is financed by credit from leveraged institutions (Crowe et al. 2011).

For the purpose in this paper, we use the framing of externalities presented and discussed in De Nicolò et al. (2012). The negative externalities are illustrated in Fig. 10 in a stylized credit cycle. ${ }^{26}$

In phase 1 of the credit cycle, GDP growth is usually high and the situation is characterized by rapidly rising credit volumes and asset prices, for both real and financial assets. This phase involves banks, households and firms taking on increasing amounts of debt, an increase in the risk associated with over-borrowing and in increase in risk correlation. Phase 2 originates when a financial crisis is triggered. On the back of falling asset prices, the banks experience capital adequacy problems, which must be remedied. Phase 2 means that banks liquidate large parts of the financial imbalances that were built up during phase 1 . In phase 3 , the mechanisms behind the problem are very similar to those driving the banks in phase 2 , i.e. balance sheet restructuring by firms and households. It should be emphasized that the above description is schematic. Phase 2 need not be preceded by phase 1, and phase 3 need not be preceded by phases 1-2, which constitute another argument for a broad approach.

\footnotetext{
26 The choice of three phases is made mainly on pedagogical grounds and should not be seen as in contrast or as an alternative to earlier corner stones in the literature, e.g. Minsky (1992) and Kindleberger (2000). Footnote 26 continued

Thus, this paper's naming and numbering of the phases is not the main issue, rather the stylized credit cycle should be viewed as a link between the negative externalities and the transmission channels.
} 


\section{The transmission channels}

The financial system mainly affects the real economy through the following transmission channels: the balance sheet channel, the interest rate channel, the bank capital channel and the uncertainty channel. ${ }^{27}$

The balance sheet channel describes how falling asset prices, e.g. house prices and stock prices, reduce the value of assets held by households and businesses. ${ }^{28}$ If the value of assets used as security for loans falls, lenders can tighten collateral requirements at the same time as the loan terms get worse, e.g. because the lending rate is higher or because the borrower is not allowed to borrow as much as they may want to. Next, this weighs even further on asset prices, leading to a financial accelerator effect and ultimately to a slowdown in consumption and investment.

The interest rate channel describes how the real economy is affected when market interest rates rise, for example because the central bank increases the repo rate. Rising market interest rates lead to higher financing costs for banks and consequently to higher lending rates. ${ }^{29}$ This, in turn, leads to a slowdown in consumption/investments by households/businesses. ${ }^{30}$ can have a negative effect on the price of financial and real assets because the present value of future returns from these assets decreases. Consumption also decreases as a result of this wealth effect.

The bank capital channel describes how different types of risk associated with the operations of banks (e.g. market risk, credit risk and financing risk) worsen bank balance sheets by, for example, reducing the value of the bank's assets and equity. ${ }^{31}$ However, banks must meet certain requirements concerning capital adequacy, solvency and liquidity. Banks can choose to either raise their lending rates (thereby increasing their profit and equity) and/or reduce their lending to be able to fulfil these requirements which lead to lower consumption and less investment.

The uncertainty channel describes how more uncertainty in the form of price fluctuations in financial markets, i.e. greater volatility, leads to higher precautionary savings and lowers consumption as well as less investment. ${ }^{32}$

\footnotetext{
27 The interested reader is referred to Basel Committee (2011, 2012a, b); Antony and Broer (2010); Ministry of Finance (2013); Gerke et al. (2012) for summaries of the latest research in this area.

28 Along with the interest rate channel, it is also called the credit channel. See, for example, Bernanke and Gertler (1989); Bernanke et al. (1998); Kiyotaki and Moore (1997); Holmström and Tirole (1997).

29 In principle, the policy rate is assumed to have an immediate effect on short-term market rates and lagged effect on long-term rates.

30 Monetary policy can also affect the economy via the "exchange rate channel". An increase in the policy interest rate normally leads to exchange rate appreciation. A stronger exchange rate means lower import prices, with the result that some domestic demand moves from domestic to imported goods. This moderates the inflationary pressure and also leads to a weaker balance of trade. Moreover, monetary policy also affects the economy through other channels via expectations.

31 See, for example, Stein (1998) and Heuvel (2002, 2004).

32 See, for example, Antony and Broer (2010).
} 


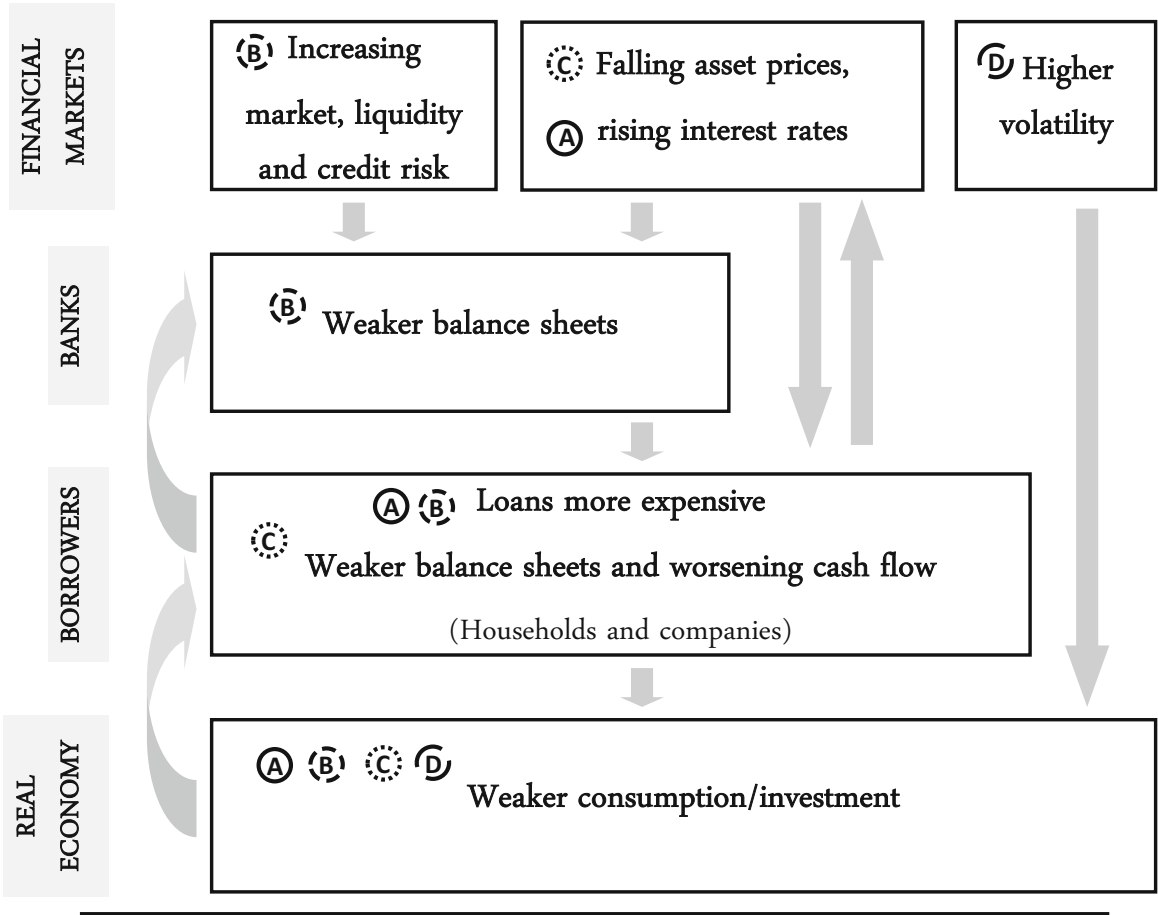

\section{(A) Interest rate channel Balance sheet channel (B) Bank capital channel D Uncertainty channel}

Fig. 11 Transmission mechanism flow chart, including the three main areas of the credit cycle's negative external effects

\section{The linkages between negative externalities and transmission channels}

The negative external effects can also be described in terms of their effect on three main areas of the economy: (i) market liquidity, (ii) the supply of credit and (iii) the demand for credit. Depending on the channel, the effects go via the financial markets, the banks and/or households and firms before finally affecting the real economy. Dividing the negative externalities into these three main areas allows us to illustrate how they affect the real economy through various transmission channels as illustrated in Fig. 11. The different transmission channels in the economy have been marked by letters $A$ to $D$ in the figure; (A) the interest rate channel; (B) the bank capital channel; (C) the balance sheet channel; and (D) the uncertainty channel. ${ }^{33}$

Information contagion and fire sales are typical externalities affecting market liquidity during phase 2 , characterized by major volatility and rapid general declines in

\footnotetext{
${ }^{33}$ Figure 8 is schematic and should not be interpreted as saying that the four transmission channels are independent of one another.
} 
financial markets. Heightened volatility leads to increased uncertainty and is followed by greater caution, thus curbing demand in the economy (the uncertainty channel).

The effects on the supply of credit occur in both phase 1 and phase 2, and intensify the upturn or downturn. In phase 2, a higher degree of interconnectedness between financial institutions intensifies the shocks, which exacerbates the credit contraction or results in higher lending rates. This, in turn, leads to a fall in demand in the real economy (bank capital channel).

The effects on the demand of credit occur in both phase 1 and phase 3 but is perhaps most tangible in phase 3 when households and firms react to the decline in asset prices. In order to reduce their debt ratio, households increase their precautionary saving, which reduces aggregated demand in the economy (the balance sheet channel).

\section{References}

Abildgren K (2012) Business cycles and shocks to financial stability: empirical evidence from a new set of Danish quarterly national accounts 1948-2010. Scand Econ Hist Rev 60:50-78

Adalid R, Detken C (2007) Liquidity shocks and asset price boom/bust cycles. Working Paper No. 732, European Central Bank

Adolfson M, Laséen S, Lindé J, Villani M (2005) Are constant interest rate forecasts modest policy interventions? Evidence from a dynamic open-economy model. Int Finance 8:509-544

Adolfson M, Andersson M, Lindé J, Villani M, Vredin A (2007) Modern forecasting methods in action: improving macroeconomic analyses at central banks. Int J Cent Bank 3:111-144

Adolfson M, Laséen S, Christiano L, Trabandt M, Walentin K (2013) Ramses II-Model description. Occasional Paper No. 12, Sveriges Riksbank

Antony J, Broer P (2010) Linkages between the financial and the real sector of the economy: a critical survey. CPB Document No. 216, CPB Netherlands Bureau for Economic Policy Analysis

Arregui N, Benes J, Krznar I, Mitra S, Santos AO (2013) Evaluating the net benefits of macroprudential policy: a cookbook. Working Paper No. 13/167, International Monetary Fund

Bańbura M, Giannone D, Reichlin L (2010) Large Bayesian vector auto regressions. J Appl Econom 25:7192

Bańbura M, Giannone D, Lenza M (2015) Conditional forecasts and scenario analysis with vector autoregressions for large cross-sections. Int J Forecast 31:739-756

Basel Committee on Banking Supervision (2011) The transmission channels between the financial and real sectors: a critical survey of the literature. BCBS Working Paper No. 18, Bank for International Settlements

Basel Committee on Banking Supervision (2012a) The policy implications of transmission channels between the financial and the real economy. BCBS Working Paper No. 20, Bank for International Settlements

Basel Committee on Banking Supervision (2012b) Models and tools for macroprudential analysis. BCBS Working Paper No. 21, Bank for International Settlements

Bernanke B, Gertler M (1989) Agency costs, net worth and business fluctuations. Am Econ Rev 79:14-31

Bernanke B, Gertler M, Gilchrist S (1998) The financial accelerator in a quantitative business cycle framework. Working Paper No. 6455, National Bureau of Economic Research

Bloom N (2009) The impact of uncertainty shocks. Econometrica 77:623-685

Bloom N, Floetotto M, Jaimovich N, Saporta-Eksten I, Terry S J (2012) Really uncertain business cycles. Working Paper No. 18245, National Bureau of Economic Research

Brunnermeier K, Eisenbach M T, Sannikov Y (2012) Macroeconomics with financial frictions: a survey. Working Paper No. 18102, National Bureau of Economic Research

Christiano LJ, Eichenbaum M, Evans CL (1996) The effects of monetary policy shocks: evidence from the flow of funds. Rev Econ Stat 78:16-34

Christiano LJ, Eichenbaum M, Evans CL (1999) Monetary policy shocks: What have we learned and to what end? In: Taylor JB, Woodford M (eds) Handbook of macroeconomics, vol I. North-Holland, Amsterdam, pp 65-148

Christiano LJ, Motto R, Rostagno M (2014) Risk shocks. Am Econ Rev 104:27-65 
Clark T (2011) Real-time density forecasts from Bayesian vector autoregressions with stochastic volatility. J Bus Econ Stat 29:327-341

Crowe C, Dell'Ariccia G, Igan D, Rabanal P (2011) Policies for macrofinancial stability: options to deal with real estate booms. Staff Discussion Notes No. 11/2, International Monetary Fund

De Nicolò G, Favara G, Ratnovski L (2012) Externalities and macroprudential policy. Staff Discussion Notes No. 12/5, International Monetary Fund

Drehmann M, Borio C, Gambacorta L, Trucharte C (2010) Countercyclical capital buffers: exploring options. Working Paper No. 317, Bank for International Settlements

Eichenbaum M, Evans CL (1995) Some empirical evidence on the effects of shocks to monetary policy on exchange rates. Q J Econ 110:975-1009

Espinoza R, Fornari F, Lombardi MJ (2012) The role of financial variables in predicting economic activity. J Forecast 31:15-46

Fornari F, Lemke W (2010) Predicting recession probabilities with financial variables over multiple horizons. Working Paper No. 1255, European Central Bank

Fornari F, Stracca L (2013) What does a financial shock do? First international evidence. Working Paper No. 1522, European Central Bank

Forss Sandahl J, Holmfeldt M, Rydén A, Strömqvist M (2011) An index of financial stress for Sweden. Sver Riksbank Econ Rev 2011(2):49-66

George EI, Sun D, Ni S (2008) Bayesian stochastic search for VAR model restrictions. J Econom 142:553580

Gerke R, Jonsson M, Kliem M, Kolasa M, Lafourcade P, Locarno A, Makarski K, McAdam P (2012) Assessing macro-financial linkages: a model comparison exercise. Discussion Paper No. 02/2012, Deutsche Bundesbank

Gerlach S, Smets F (1995) The monetary transmission mechanism: evidence from G7 countries. BCBS Working Paper No. 26, Bank for International Settlements

Giannone D, Lenza M, Primiceri GE (2015) Prior selection for vector autoregressions. Rev Econ Stat 97:436-451

Goodhart C, Hofmann B (2008) House prices, money, credit and the macroeconomy. Working Paper No. 888, European Central Bank

Hanson SG, Kashyap AK, Stein JC (2011) A macroprudential approach to financial regulation. J Econ Perspect 25:3-28

Holló D, Kremer M, Lo Duca M (2012) CISS - A composite indicator of systemic stress in the financial system. Working Paper No. 1426, European Central Bank

Holmfeldt M, Rydén A, Strömberg L, Strömqvist M (2009) How has stress on financial markets developed? Discussion based on index. Economic Commentary No. 13, Sveriges Riksbank

Holmström B, Tirole J (1997) Financial intermediation, loanable funds and the real sector. Q J Econ 112:663-691

Hubrich K, D’Agostino A, Ĉervená M, Ciccarelli M, Guarda P, Haavio M, Jeanls P, Mendicino C, Ortega E, Valderrama MT, Endrész MV (2013) Financial shocks and the macroeconomy: heterogeneity and non-linearities. Occasional Paper No. 143, European Central Bank

IMF (2015) Balance sheet analysis in fund surveillance. Policy Paper June 2015, International Monetary Fund

Jarocinski M, Smets F (2008) House prices and the stance of monetary policy. Fed Reserve Bank St Louis Rev 90:339-365

Jermann U, Quadrini V (2012) Macroeconomic effects of financial shocks. Am Econ Rev 102:238-271

Johansson T (2013) Bonthron F (2013) Further development of the index for financial stress for Sweden. Sver Riksbank Econ Rev 1:46-65

Karlsson S (2013) Forecasting with Bayesian vector autoregression. In: Elliot G, Timmermann A (eds) Handbook of economic forecasting, vol 2, Part B. North-Holland, Amsterdam, pp 791-897

Karlsson M, Shahnazarian H, Walentin K (2009) Vad bestämmer bankernas utlåningsräntor? (What decides bank lending rates?). Ekon debatt 37:11-22

Kashyap AK, Berner R, Goodhart C (2011) The macroprudential toolkit. IMF Econ Rev 59:145-161

Kindleberger CP (2000) Manias, panics and crashes: a history of financial crises, 4th edn. Wiley, New York

Kiyotaki N, Moore J (1997) Credit cycles. J Polit Econ 105:211-248

Koop G, Korobilis D (2010) Bayesian multivariate time series methods for empirical macroeconomics. Found Trends Econom 3:267-358

Korobilis D (2013) VAR forecasting using Bayesian variable selection. J Appl Econom 28:204-230 
Litterman R (1979) Techniques of forecasting using vector autoregressions. Working Paper No. 115, Federal Reserve Bank of Minneapolis

López-Salido D, Stein CJ, Zakrajšek E (2016) Credit-market sentiment and the business cycle. Working Paper No. 21879, National Bureau of Economic Research

Louzis D (2015) Steady-state priors and Bayesian variable selection in VAR forecasting. Stud Nonlinear Dyn Econom. doi:10.1515/snde-2015-0048

Ministry of Finance (2013) The interaction between the financial system and the real economy. Report from the Economic Affairs Department at the Ministry of Finance, Stockholm

Minsky HP (1992) The financial instability hypothesis. Working Paper No. 74, Jerome Levy Economics Institute

Österholm P (2010) The effect on the Swedish real economy of the financial crisis. Appl Financ Econ 20:265-274

Österholm P (2012) The limited usefulness of macroeconomic Bayesian VARs when estimating the probability of a US recession. J Macroecon 34:76-86

Perotti EC, Suarez J (2009) Liquidity insurance for systemic crises. Policy Insight No. 31, Centre for Economic Policy Research

Rabanal P, Taheri Sanjani M (2015) Financial factors: implications for output gaps. Working Paper No. 15/153, International Monetary Fund

Rubio-Ramírez JF, Waggoner DF, Zha T (2010) Structural vector autoregressions: theory or identification and algorithms for inference. Rev Econ Stud 77:665-696

Shin H (2010) Macroprudential policies beyond Basel III. Policy Memo

Sims C (1992) Interpreting the macroeconomic time series facts: the effects of monetary policy. Eur Econ Rev 36:975-1000

Stein JC (1998) An adverse selection model of bank asset and liability management with implications for the transmission of monetary policy. RAND J Econ 29:466-486

van den Heuvel SJ (2002) Does bank capital matter for monetary transmission? Fed Reserve Bank N Y Econo Policy Rev 8:259-265

van den Heuvel SJ (2004) The bank capital channel of monetary policy. Mimeo, University of Pennsylvania, Philadelphia

van Roye B (2014) Financial stress and economic activity in Germany. Empirica 41:101-126

Villani M (2009) Steady state priors for vector autoregressions. J Appl Econom 24:630-650 